\title{
Modelling and Validation of Atmospheric Expansion and Near-Field Dispersion for Pressurised Vapour or Two-Phase Releases
}

\author{
Henk W.M. Witlox*, Maria Fernandez, Mike Harper, and Jan Stene \\ DNV GL Software, Palace House, 3 Cathedral Street, London SE1 9DE, UK \\ *Corresponding Author: Tel: +44 20381 65972,E-mail: henk.witlox@dnvgl.com
}

\begin{abstract}
The consequence modelling package Phast includes steady-state and time-varying discharge models for vessel orifice releases of toxic or flammable materials. These models first calculate the depressurisation between the stagnation and orifice conditions and subsequently impose the 'ATmospheric EXpansion model' ATEX for modelling the expansion from orifice conditions to the final conditions at atmospheric pressure. The latter post-expansion conditions are used as the source term for the Phast 'Unified Dispersion Model' UDM.
\end{abstract}

The ATEX mathematical model determines the unknown post-expansion variables (diameter, velocity, temperature, liquid fraction, density and enthalpy) by imposing conservation of mass and energy, and equations of state for density and enthalpy. In addition, conservation of either momentum or entropy is imposed; by default the conservation option which results in the minimum change in temperature and/or liquid fraction is used. Finally a maximum is imposed for the post-expansion velocity.

The current paper summarises the results of a literature review on atmospheric expansion modelling, and provides recommendations on selection of ATEX model equations to ensure a most accurate prediction for the near-field UDM jet dispersion against available experimental data.

First, the correctness of the numerical solution to the ATEX equations has been verified against an analytical solution of ideal-gas releases for both cases of isentropic and conservation-ofmomentum assumptions, including comparison against published data in the literature. Also the importance of non-ideal gas effects is investigated.

Secondly, both ATEX expansion options have been applied to known available experimental data for orifice releases. This includes gas jets (natural gas and ethylene - British gas experiments, hydrogen - Shell/HSL experiments) and flashing liquid jets (ammonia - Desert 
Tortoise, Fladis; propane - EEC; HF - Goldfish; $\mathrm{CO}_{2}-\mathrm{CO} 2 \mathrm{PIPETRANS}$ ). For these experimental data it was confirmed that the ATEX conservation-of-momentum option without a velocity cap provides overall more accurate concentration predictions than the isentropic assumption. However the existing default 'minimum thermodynamic change' option was found to mostly impose conservation of entropy (velocity cap not applicable) for two-phase releases and conservation of momentum (velocity cap applicable) for the sonic gas jets. Rainout calculations for flashing two-phase releases are currently always based on the isentropic assumption, which is inconsistent with the recommended conservation of momentum; a further investigation is recommended.

Keywords: consequence modelling, discharge, dispersion, model verification, model validation, hydrogen

\section{INTRODUCTION}

The consequence modelling software package Phast and the QRA software package Safeti include steady-state (DISC) and time-varying (TVDI)) discharge models for vessel orifice releases of toxic or flammable materials. These models first calculate the depressurisation between the stagnation and downstream orifice (vena contracta) conditions by conserving energy and entropy. Subsequently the 'Atmospheric Expansion model' ATEX is imposed for modelling the expansion from downstream orifice conditions to the final conditions at atmospheric pressure. The latter post-expansion conditions are used as the source term for the Phast dispersion model UDM.

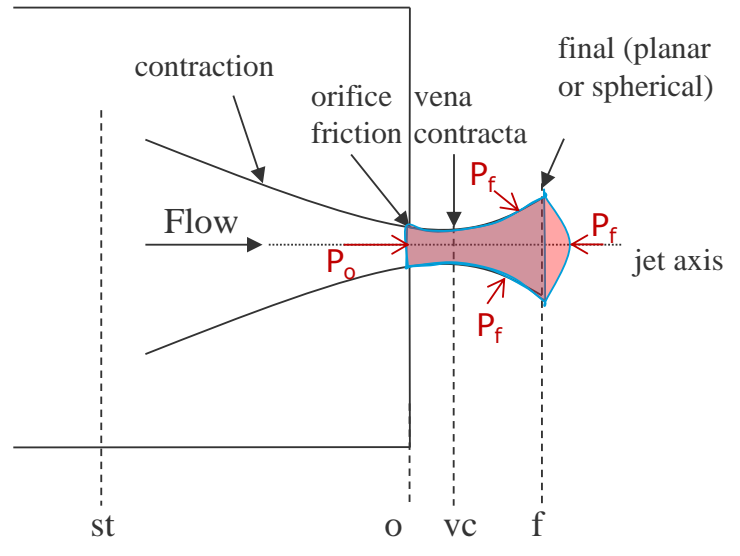

(a) Flow regimes for discharge from orifice

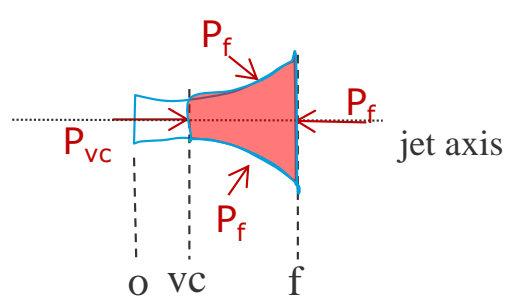

(b) ATEX control volume

Figure 1. Control volume for expansion to ambient conditions

Figure 1a illustrates the subsequent flow regimes for the case of the discharge from an orifice:

- (st) stagnation point (zero velocity, pressure $\mathrm{P}_{\mathrm{st}}$, temperature $\mathrm{T}_{\mathrm{st}}$ )

- (o) upstream orifice (nozzle entrance; area $\mathrm{A}_{\mathrm{o}}$, velocity $\mathrm{u}_{\mathrm{o}}$, pressure $\mathrm{P}_{\mathrm{o}}$, temperature $\mathrm{T}_{\mathrm{o}}$ )

- (vc) downstream orifice (nozzle throat; vena contracta area $A_{v c}$, velocity $u_{v c}$, pressure $\mathrm{P}_{\mathrm{vc}}$, temperature $\left.\mathrm{T}_{\mathrm{vc}}\right)$ 
- (f) end of atmospheric expansion zone (area $A_{f}$, velocity $u_{f}$, pressure $P_{f}=$ ambient pressure $\mathrm{P}_{\mathrm{a}}$, temperature $\mathrm{T}_{\mathrm{f}}$ )

The vena contracta area equals $A_{v c}=C_{d} A_{o}$, where $C_{d}$ equals the discharge coefficient. At the vena contracta, DISC and TVDI applies the metastable liquid assumption (100\% liquid, pressure $=$ ambient pressure) in case of liquid storage, and thermodynamic equilibrium in case of vapour storage. At the final conditions (f) the flow is presumed to be thermodynamically stable. ATEX presumes the final surface to be a plane surface (Figure 1b), while Paris et al. (2005) presume the final surface to be part of a sphere (Figure 1a).

\section{$\underline{\text { ATEX atmospheric expansion model }}$}

The ATEX model solves five equations to determine five unknown variables at the final surface, i.e. area $A_{f}$, velocity $u_{f}$, temperature $T_{f}$ or liquid fraction $f_{L f}$, density $\rho_{f}$ and enthalpy $h_{f}$ :

$$
\begin{gathered}
\rho_{f} A_{f} u_{f}=\rho_{v c} A_{v c} u_{v c} \text {, mass conservation } \\
\rho_{f} A_{f} u_{f}^{2}=\rho_{v c} A_{v c} u_{v c}{ }^{2}+\left(P_{v c}-P_{f}\right) A_{v c} \text {, momentum conservation } \\
\rho_{f} A_{f} u_{f}\left[h_{f}+\frac{1}{2} u_{f}{ }^{2}\right]=\rho_{v c} A_{v c} u_{v c}\left[h\left(P_{v c}, T_{v c} ; f_{L v c}\right)+\frac{1}{2} u_{v c}{ }^{2}\right] \text {, energy conservation } \\
\rho_{f}=\rho_{f}\left(P_{a}, T_{f} ; f_{L f}\right) \text {, density equation of state } \\
h_{f}=h\left(P_{a}, T_{f} ; f_{L f}\right)=f_{L f} h_{L}\left(P_{a}, T_{f}\right)+\left(1-f_{L f}\right) h_{V}\left(P_{a} T_{f}\right) \text {, enthalpy equation of state }
\end{gathered}
$$

Phast currently caps by default the final velocity $u_{\mathrm{f}}$ with $500 \mathrm{~m} / \mathrm{s}$. This capped velocity is then used in conjunction with the conservation-of-energy Equation (3) to determine the final temperature $\mathrm{T}_{\mathrm{f}}$ and liquid fraction $\mathrm{f}_{\mathrm{Lf}}$.

Instead of imposing the conservation-of-momentum Equation (2), ATEX also allows imposing conservation of entropy (final entropy $=$ vena-contracta entropy). By default Phast selects the method predicting the smallest thermodynamic change. Thus Phast will carry out both options of expansion modelling and use the results of the model which gives the highest final temperature. If both models give the same final temperature, then ATEX will use the results of the model which gives a final liquid fraction that is closest to the vena-contracta liquid fraction.

\section{$\underline{\text { Literature review }}$}

Phases I-IV of the droplet-modelling JIP managed by DNV Software (Witlox and Harper, 2013) very much focussed on the correct evaluation of the flow rate $(\mathrm{kg} / \mathrm{s})$ and initial post-expansion droplet size distribution (micrometre), but did not focus on correct evaluation of the postexpansion velocity, post-expansion liquid fraction (case of 2-phase releases) and temperature (case of vapour releases). A very brief review of external expansion calculations available in the literature was carried out by Witlox and Bowen (2001) as part of the first phase of the droplet modelling JIP.

The arbitrary ATEX default cap of $500 \mathrm{~m} / \mathrm{s}$ for post-expansion velocity is a known issue alongside the appropriate default choice of the ATEX expansion method (isentropic, 
conservation of momentum, or minimum thermodynamic change). The most common approach in the literature may be the absence of a cap combined with the conservation of momentum method (recommendation by EU project FLADIS and USA DTRA project; see e.g. Britter et al., 2011). ATEX currently also allows for an alternative cap (sonic velocity). However in case of choked flow (sonic velocity at orifice), supersonic turbulent flow (shock waves) is known to occur downstream of the orifice and the sonic cap may not be appropriate. Moreover the thermodynamic path may need to include non-equilibrium effects and/or slip. So far we are not aware of a published and validated formulation, which takes these effects into account.

Also important to note is that when modelling choked flows the final velocity $u_{\mathrm{f}}$ does not necessarily correspond to a physically real velocity, and is therefore sometimes referred to in literature as a 'pseudo-velocity'. The key important aspect is that this pseudo-velocity produces the correct amount of (jet) entrainment in the UDM dispersion model to ensure accurate predictions of the concentrations in the near-field. It is therefore NOT important that the predicted post-expansion velocity is close to the actual post-expansion velocity. A larger selected value for the velocity will correspond to a larger temperature drop and this may affect e.g. the plume rise for buoyant plumes; to avoid a large temperature drop, sometimes also an isenthalpic expansion or an isothermal expansion is applied in the literature instead of the conservation-of-energy assumption (e.g. Birch et al., 1987). Thus the emphasis of the current work is on conventional pseudo-source models (as could be used in Phast). CFD modelling is not considered. For example, Leeds University (Wareing et al., 2013) developed a CFD method solving rigorously the Navier Stokes equations to define the shape, velocity and temperature distribution downstream of the Mach shock region, where the flow expands to atmospheric pressure.

\section{$\underline{\text { Plan of paper }}$}

The objective of the current paper is to recommend on those atmospheric-expansion modelling options which are expected to provide most accurate results for near-field dispersion predictions. This has been carried out by means of verification of the ATEX model (to ensure that the governing equations are correctly solved numerically) and discharge and dispersion model validation against experimental data (to establish which options provide most accurate results).

Section 2 describes the analytical verification of the ATEX model for ideal gases. Also the importance of non-ideal gas effects is investigated. Section 3 includes results of validation of concentration predictions against high-pressure gas jets (natural-gas, ethylene and hydrogen releases), while Section 4 includes results of validation for two-phase jets (propane, ammonia, $\mathrm{HF}$ and $\mathrm{CO}_{2}$ releases). Section 5 summarises the main conclusions and includes recommendations for potential future work. See the more detailed report by Witlox and Fernandez (2016) for details not included in the current paper.

\section{MODEL VERIFICATION - GAS RELEASES}

For ideal gases well-known analytical expressions exist for vena contracta data $\left(\mathrm{P}_{\mathrm{vc}}, \mathrm{T}_{\mathrm{vc}}, \mathrm{u}_{\mathrm{vc}}, \rho_{\mathrm{vc}}\right)$ and flow rate $\mathrm{G}(\mathrm{kg} / \mathrm{s})$ in case of choked flow: 


$$
\begin{gathered}
\frac{P_{v c}}{P_{s t}}=\left(\frac{2}{1+\gamma}\right)^{\gamma /(\gamma-1)}, \frac{T_{v c}}{T_{s t}}=\frac{2}{1+\gamma}, \quad u_{v c}=\sqrt{\frac{R T_{s t}}{M_{w}}\left(\frac{2 \gamma}{1+\gamma}\right)}, \quad \rho_{v c}=P_{s t}\left(\frac{2}{1+\gamma}\right)^{1 /(\gamma-1)} \frac{M_{w}}{R T_{s t}} \\
G=A_{v c} \rho_{v c} u_{v c}=C_{d} A_{o} P_{s t} \sqrt{\frac{\gamma M_{w}}{R T_{s t}}\left(\frac{2}{1+\gamma}\right)^{(\gamma+1) /(\gamma-1)}}
\end{gathered}
$$

Here $\gamma=C_{p} / C_{v}$ is the gas heat capacity ratio, $M_{w}$ the gas molecular weight, and $R=8314$ $\mathrm{J} / \mathrm{K} / \mathrm{kmol}$ the gas constant. Using the conservation-of-energy equation (3) and

$$
C_{p}=\frac{\gamma M_{w} R}{\gamma-1}, \quad h_{f}-h_{v c}=C_{p}\left(T_{f}-T_{v c}\right)
$$

the final temperature $T_{f}$ can be evaluated as function of $u_{f}$ as

$$
\frac{T_{f}}{T_{v c}}=1+\frac{u_{v c}^{2}}{2 C_{p} T_{v c}}\left[1-\left(\frac{u_{f}}{u_{v c}}\right)^{2}\right]=1+\frac{\gamma-1}{2}\left[1-\left(\frac{u_{f}}{u_{v c}}\right)^{2}\right]
$$

The final velocity $u_{f}$ in the above equation can be set by using Equation (6) into conservation-ofmomentum equation (2).

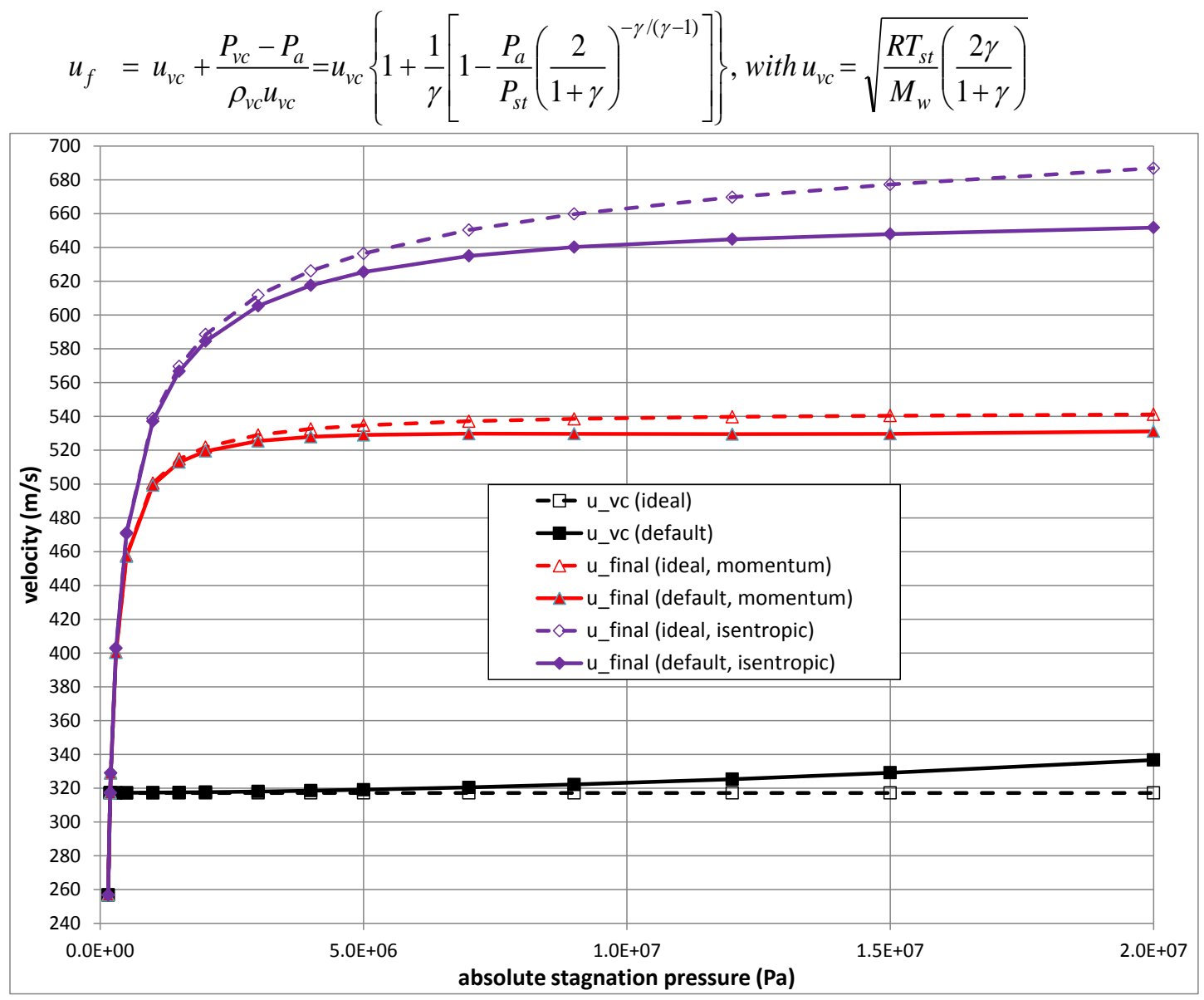

(a) velocity 


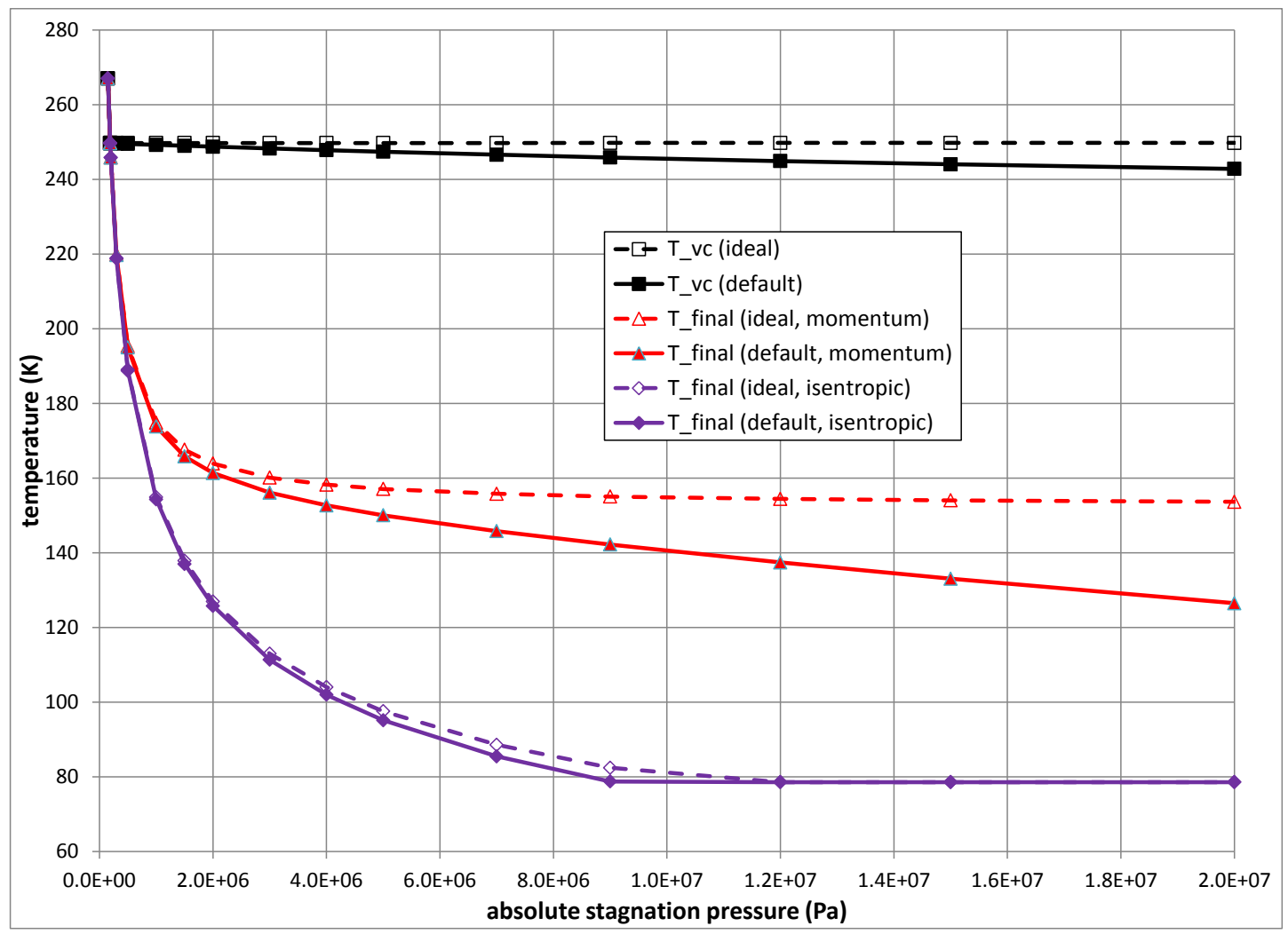

(b) temperature

Figure 2. Air jets - vena-contracta/final velocities/temperatures versus stagnation pressure Likewise an analytical expression can be derived in case of the isentropic option. The numerical solution of the Phast orifice discharge calculations was verified against the above analytical solution for a sonic air jet, and identical results were confirmed when imposing the ideal-gas equation of state (EOS) in Phast.

Yüceil and Ötügen (2002) also derive the above equation (9) for the final temperature and their model is fully in line with the ATEX conservation of momentum model for the case of a sonic jet (Mach number $\mathrm{M}_{\mathrm{vc}}=1$ ). They also present analytical formulas for the final velocity, final density and the final diameter, again in line with our model. In addition they also plot the diameter increase $D_{f} / D_{v c}$ and the velocity increase $u_{f} / u_{v c}$ during the atmospheric expansion as function of $\mathrm{P}_{\mathrm{vc}} / \mathrm{P}_{\mathrm{a}}$. It was confirmed that ideal-gas EOS ATEX predictions were virtually identical to those presented by Yüceil and Ötügen.

The case is considered of a sonic air jet $\left(\gamma=1.4, \mathrm{M}_{\mathrm{w}}=28.95 \mathrm{~kg} / \mathrm{kmol}\right)$ with $25 \mathrm{~mm}$ orifice and stagnation temperature of $300 \mathrm{~K}$. Simulations were carried out using the Phast steady-state model DISC, whereby DISC imposes the ATEX model for expansion from vena-contracta to final atmospheric conditions without an application of the velocity cap. For larger stagnation pressures, the real-gas law (based on default Phast Soave-Redlich-Kwong EOS) was shown to predict slightly lower vena-contracta pressures than the ideal-gas law. Figure 2 plots DISC predictions of vena contract and final data as a function of the stagnation pressure for both velocity and temperature. Vena contracta data are given by black lines, final data based on conservation of momentum by red lines, and final data based on conservation of entropy by 
purple lines; default EOS predictions are given by solid lines and ideal-gas EOS predictions by dashed lines. It is seen that the default real-gas EOS produces lower temperatures and lower final velocities than the ideal-gas EOS. The figure also shows that the isentropic option results in significantly higher final velocities and lower final temperatures than the conservation-ofmomentum option. Thus Phast selects as default the conservation-of-momentum option since this leads to minimum thermodynamic change.

\section{MODEL VALIDATION - GAS RELEASES}

\subsection{Natural gas and ethylene jets (British Gas experiments)}

British Gas carried out experiments for natural-gas and ethylene jets (Birch et al., 1984). The gas jet was released from a nozzle with internal diameter $d_{0}=2.7 \mathrm{~mm}$. The natural gas used was quoted to have a methane content of between 92.0 and 92.4 mole \% and a mean molecular weight of $17.32 \mathrm{~kg} / \mathrm{kmol}$. In the experiments the gas was sampled continuously from the jet centre-line, and mean concentrations were measured using a rapid chromatograph. Natural-gas releases were carried out using stagnation pressures $\mathrm{P}_{\mathrm{st}}$ varying between 3.5 and 71 bara, while the ethylene experiment was carried out at 8 bara.

The natural gas was modelled as a mixture of methane and ethane, with a composition such that the mole weight equals $17.32 \mathrm{~kg} / \mathrm{kmol}$. This results in a composition of 90.9 mole $\% \mathrm{CH}_{4}$ and $9.1 \% \mathrm{C}_{2} \mathrm{H}_{6}$, i.e. reasonably close to the specified value of $92 \%$ of methane content.

DISC calculations were carried out to model the discharge for the above experiments. The calculated discharge coefficient was shown to vary between 0.83 and 0.87 in line with the value of 0.85 stated in Birch et al. (1984). For all cases the conservation-of-momentum option was selected by default. For the natural gas cases the final velocity $\mathrm{u}_{\mathrm{f}}$ (without application of cap of $500 \mathrm{~m} / \mathrm{s}$ ) was shown to vary between $536 \mathrm{~m} / \mathrm{s}$ and $654 \mathrm{~m} / \mathrm{s}$, while the velocity for the ethylene jet was $484 \mathrm{~m} / \mathrm{s}$. 


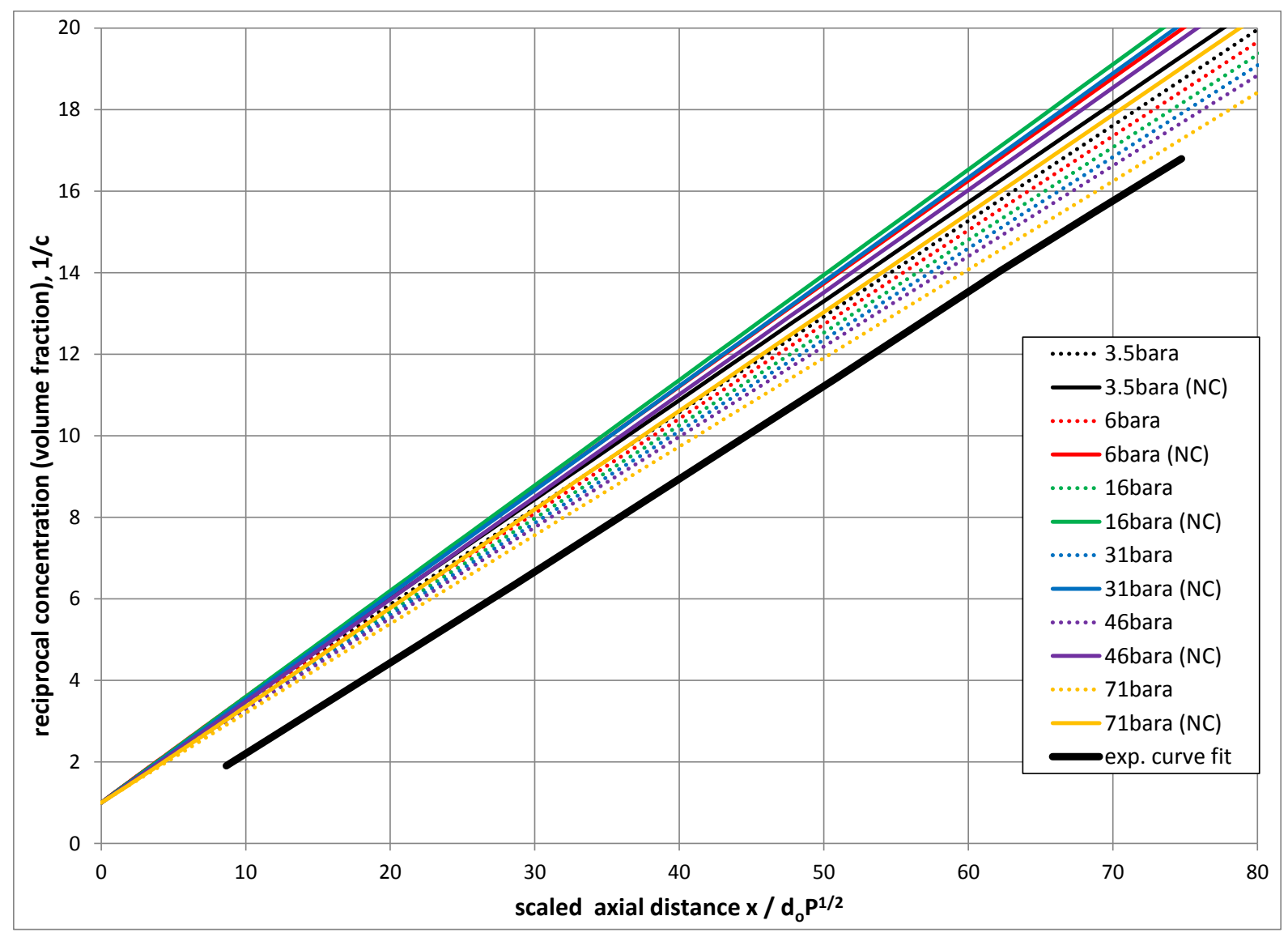

Figure 3. UDM validation against BG natural-gas experiments (stagnation pressures $\mathbf{P}_{\text {st }}=3.5-71$ bara)

Subsequently UDM dispersion calculations were carried out, where the near-field air entrainment for the high-speed jet is dominated by jet entrainment; see Witlox and Holt (1999) for further details of the UDM theory. Given absence of further information, neutral conditions (stability class D with low wind-speed of $0.1 \mathrm{~m} / \mathrm{s}$ ) and a surface roughness of $0.01 \mathrm{~m}$ were presumed. For the natural gas experiments, Birch et al. (1984) plotted the reciprocal concentration (1/c, with c being volume fraction of natural-gas) against the scaled axial distance $\mathrm{x} /\left[\mathrm{d}_{\mathrm{o}} \mathrm{P}_{\mathrm{st}}{ }^{1 / 2}\right]$ and his experimental data could closely be fitted by a straight line. Figure 3 includes this experimental fit as well as predictions from the above UDM runs.

For simulations without a cap (indicated in Figure 3 by NC) concentrations c will be smaller (and hence $1 / \mathrm{c}$ larger) due to a larger value of the initial velocity $\mathrm{u}_{\mathrm{f}}$ and hence larger jet entrainment. It is seen that the reciprocal concentration $1 / \mathrm{c}$ is slightly over-predicted, and therefore the concentration is under-predicted. The latter under-prediction could also be (partly) caused by under-prediction of the flow rate. The under-prediction is slightly larger for those cases without a cap than with a cap. Also note that the experiment fitted curve (while extrapolating to $\mathrm{x}=0 \mathrm{~m}$ ) appears to cross the point $x=0, c=0$ while it SHOULD cross the point $x=0, c=1(100 \%$ centre-line concentration at the release location). Thus this may indicate some inaccuracy in the concentration measurements. Therefore taking the above into account, it is concluded that close agreement is obtained with the experimental data for both with and without a cap. 


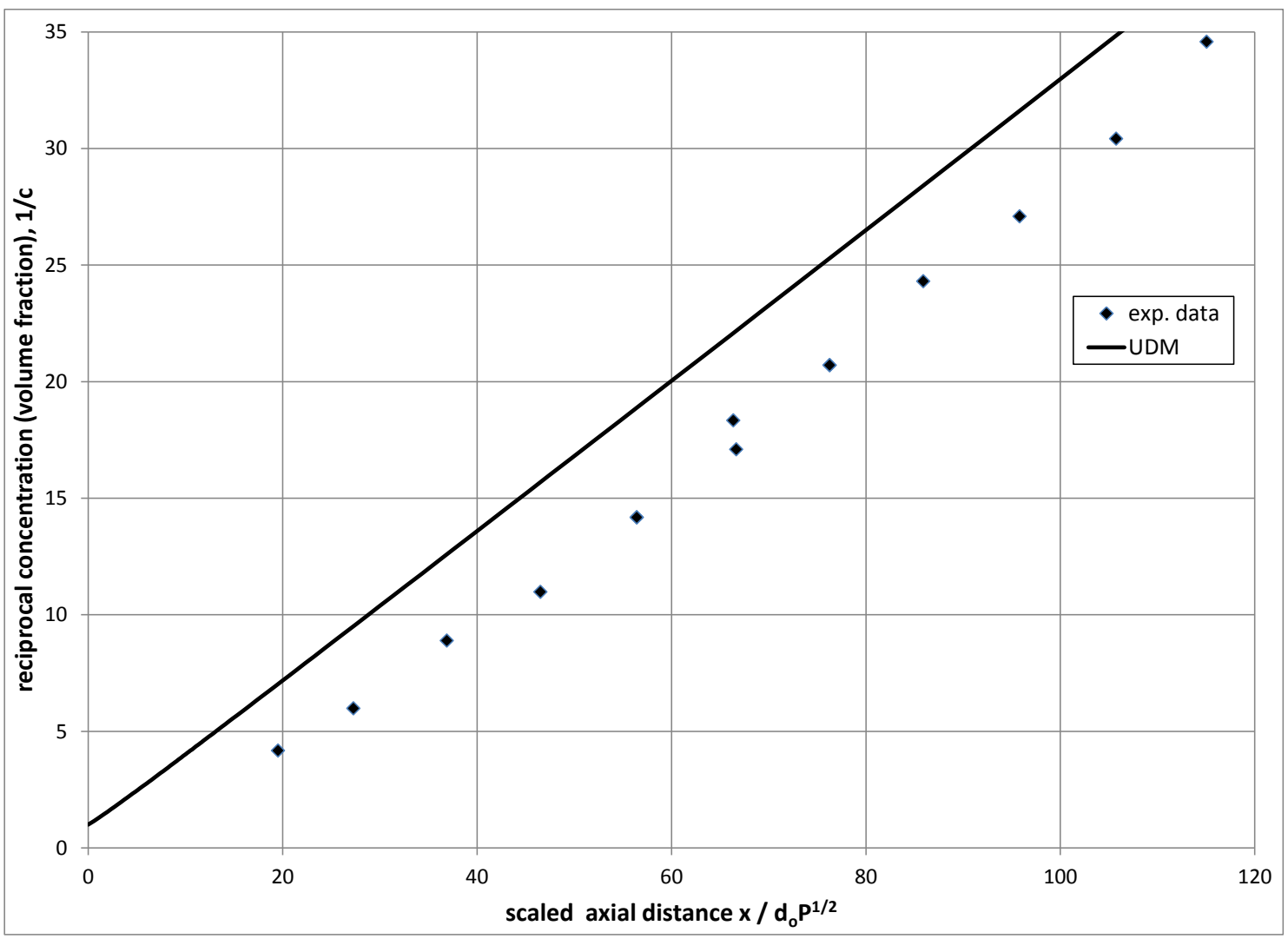

Figure 4. UDM validation against BG ethylene experiment (stagnation pressure $P_{\text {st }}=8 \mathrm{bara}$ )

Birch (1984) also plotted the reciprocal concentration (1/c) versus the scaled axial distance $\mathrm{x} /\left[\mathrm{d}_{\mathrm{o}} \mathrm{P}_{\mathrm{st}}{ }^{1 / 2}\right]$ for the ethylene experiment, and it was again seen that the concentration was slightly under-predicted; see Figure 4.

\subsection{Hydrogen jets (Shell/HSL experiments)}

Commissioned by Shell Global solutions, HSL carried out experimental work relating to horizontal pressurised hydrogen orifice releases at $1.5 \mathrm{~m}$ above the ground.

Roberts et al. (2006) discusses results of a set of 23 experiments for which the flow rate was unsatisfactorily not measured. For these experiments the hole diameter equals 3, 4, 6 or $12 \mathrm{~mm}$, the stagnation temperature varies between 13 and $20 \mathrm{C}$ and the stagnation pressure varies between 10 barg and 129 barg. The paper compares predicted concentrations against the HGSYSTEM model AEROPLUME. The paper states that good results were obtained for 8 experiments which pointed close towards the wind direction (limited crosswind effects; runs 6, 7, $8,9,10,11,14,16 ; 3 \mathrm{~mm}$ or $4 \mathrm{~mm}$ orifice size, stagnation temperature around $14 \mathrm{C}$ and stagnation pressure 50-118 barg).

Skottene and Holm (2008) carried out validation using Phast against the hydrogen HSL experiments. They also refer to an additional set of experiments with smaller orifice diameters 
$(0.25,0.75$ and $1 \mathrm{~mm})$ for which the flow rate was measured, and for which the results are not reported in the paper by Roberts et al. (2006).

As part of the current work, first DISC discharge simulations were carried out for the small orifice sizes (0.25, 0.75 and $1 \mathrm{~mm}$; pressures ranging between 93 and $207 \mathrm{barg})$, for which experimental measurements of the flow rate are available. Identical results were obtained as those reported by Skottene and Holm (2008), with a slight under-prediction of the flow rate between $6 \%$ and $8 \%$. Thus the flow rates are very accurately predicted for these experiments.

Secondly DISC and UDM simulations were carried out for the larger orifice diameters 3 and $4 \mathrm{~mm}$, for which no experimental measurements of the flow rate are available. For these experiments flow rate predictions were compared with results of the HGSYSTEM model AEROPLUME reported by Roberts et al. (2006). Close agreement was found with HGSYSTEM assuming a discharge coefficient $\mathrm{C}_{\mathrm{d}}=1$, while using the default $\mathrm{C}_{\mathrm{d}}(\approx 0.86)$ the DISC flow rate is about $14 \%$ lower. Thus it appears that HGSYSTEM applies $C_{d}=1$.

The concentration measurements were taken along the release axis (i.e. at $1.5 \mathrm{~m}$ height) and distances 3, 4, 5, 6, 7, 8, 9, 10, $11 \mathrm{~m}$ from the release orifice. DISC and UDM simulations were carried out for test 7 (stagnation pressure 99 barg, stagnation temperature $14 \mathrm{C}$, orifice $3 \mathrm{~mm}$, wind speed $1 \mathrm{~m} / \mathrm{s})$, test 9 (92 barg, $13.5 \mathrm{C}, 4 \mathrm{~mm}, 3 \mathrm{~m} / \mathrm{s})$ and test 14 (49 barg, $13.5 \mathrm{C}, 3 \mathrm{~mm}, 3$ $\mathrm{m} / \mathrm{s})$. Simulations were carried out with final-velocity cap $(500 \mathrm{~m} / \mathrm{s}$ ) and without cap (around $2000 \mathrm{~m} / \mathrm{s})$, as well as with discharge coefficient calculated $\left(\mathrm{C}_{\mathrm{d}} \approx 0.86\right)$ and with $\mathrm{C}_{\mathrm{d}}=1$. Neutral conditions and a surface roughness of $0.01 \mathrm{~m}$ were presumed.

Figure 5 includes UDM predictions for test 7. For each of the DISC model assumptions (without and with velocity cap, $\mathrm{C}_{\mathrm{d}}=1$ or calculated) results are given for the centre-line height and concentration as function of downwind distance. UDM results with a velocity cap are given by the blue curves (calculated $\left.C_{d}\right)$ and red curves $\left(C_{d}=1\right)$, while results without a velocity cap are given by the green curves (calculated $\left.C_{d}\right)$ and purple curves $\left(C_{d}=1\right)$. The concentration plot includes results for both the off-centre line concentration (at the measurement height of $1.5 \mathrm{~m}$ and zero crosswind distance; indicated by solid lines) and the centre-line concentration (indicated by dashed lines). The concentration plot also includes the observed experimental data at $1.5 \mathrm{~m}$ height. The following is concluded (similar conclusions also apply for tests 9 and 14):

- Without the velocity cap, the UDM input initial velocity (ATEX post-expansion velocity) is considerably larger and the UDM input initial temperature (ATEX post-expansion temperature) is considerably colder. The faster speed (more initial horizontal momentum) and the colder plume (less buoyancy) result in considerable less plume rise. Also the slightly smaller flow rate (smaller concentrations) results in slightly less plume rise for the runs with calculated $C_{d}$ than the runs with $C_{d}=1$. 


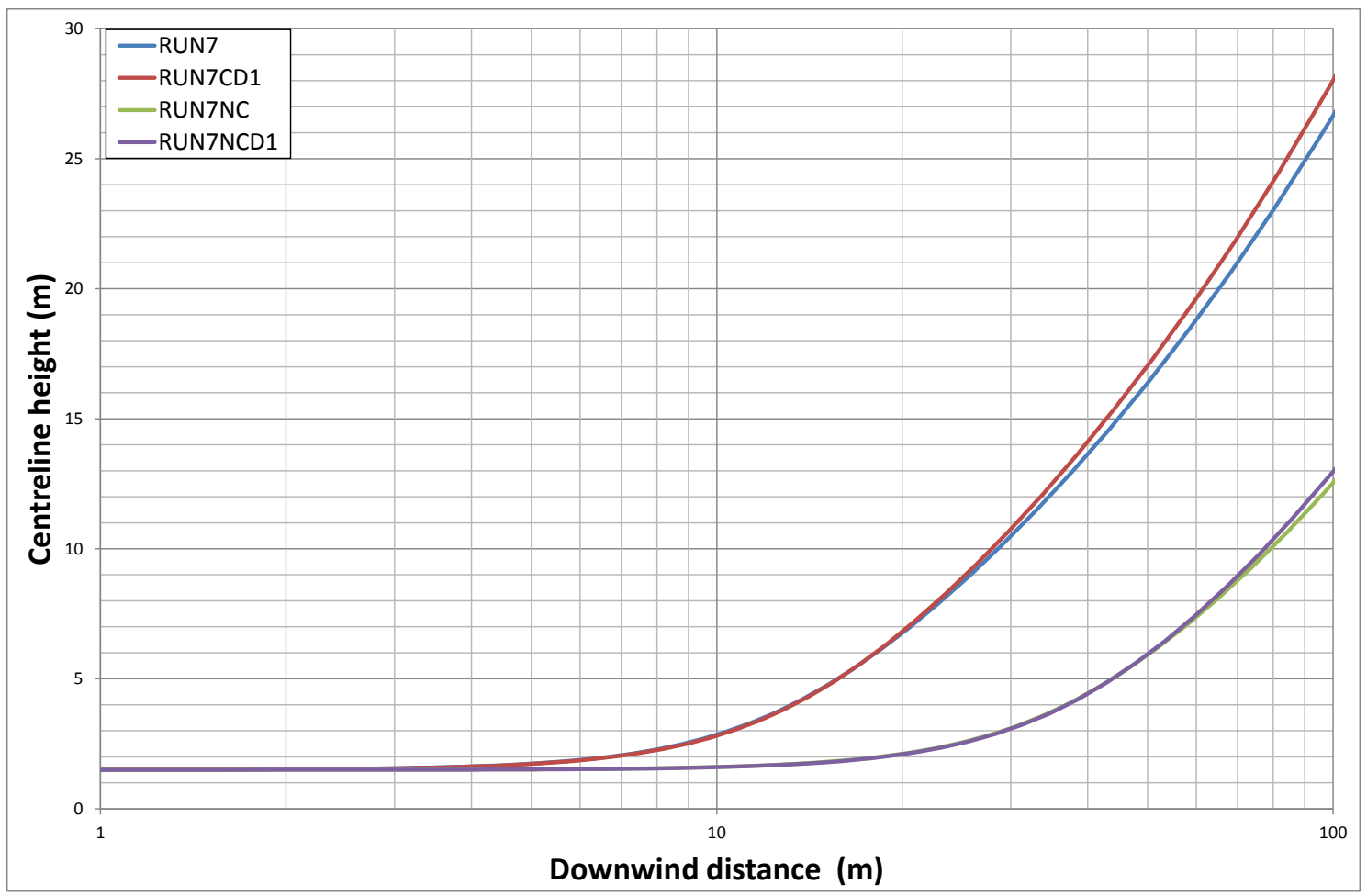

(a) Cloud centre-line height (with or without cap, $\mathrm{C}_{\mathrm{d}}=1$ or calculated)

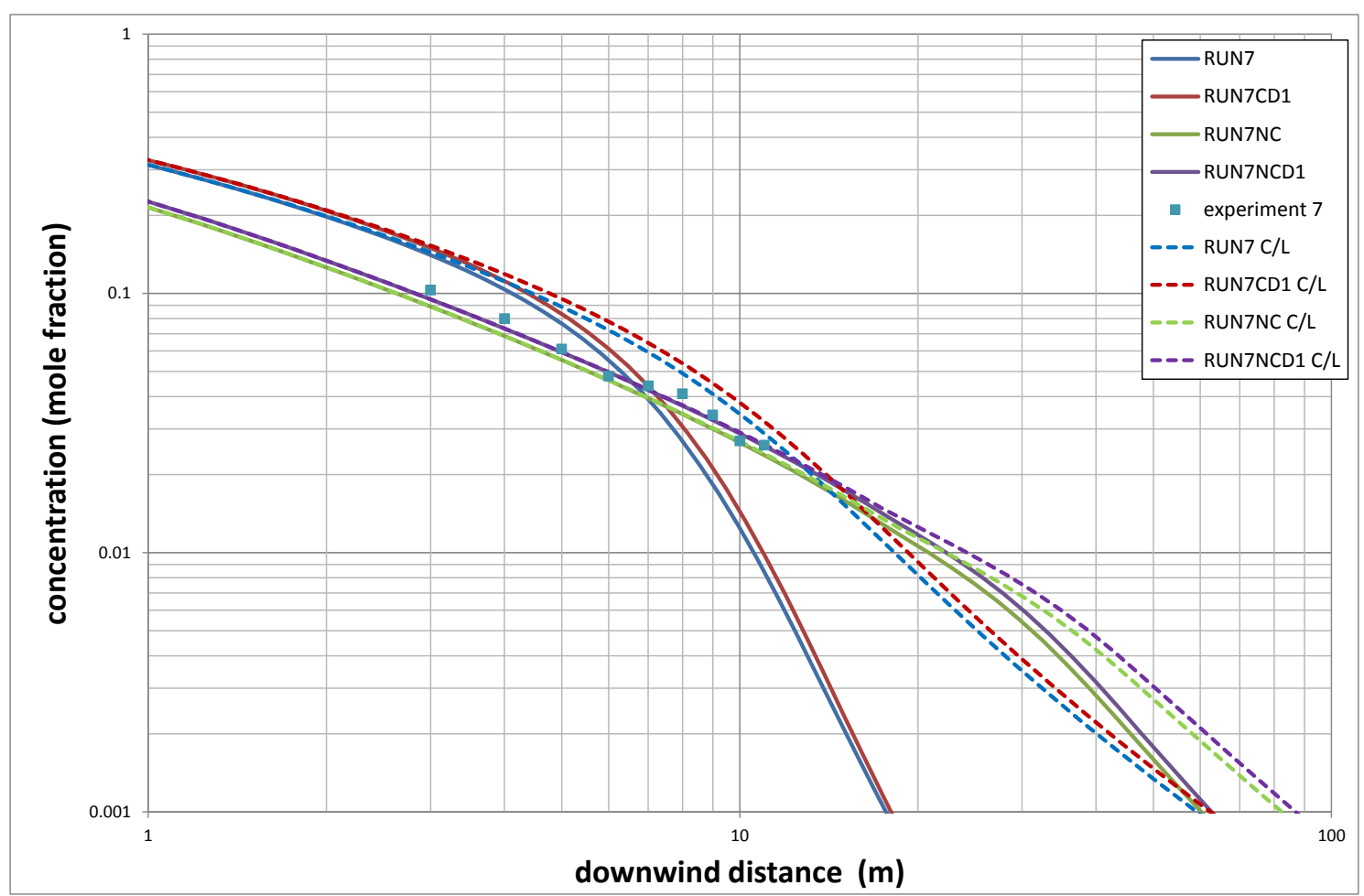

(b) Concentration (with or without cap, $\mathrm{C}_{\mathrm{d}}=1$ or calculated, at $1.5 \mathrm{~m}$ height or at centre-line height; measured concentration at $1.5 \mathrm{~m}$ height)

Figure 5. UDM validation against $\mathrm{H}_{2}$ test 7 ( $\left.3 \mathrm{~mm}, 99 \mathrm{barg}\right)$ 
- Without the velocity cap, the larger initial velocity causes significantly larger jet entrainment and therefore smaller concentrations in the near field. For the larger distances the effects of plume rise result in the concentrations at $1.5 \mathrm{~m}$ height to be smaller than the centre-line concentrations. For the larger distances the effect of reduced plume rise (and consequently smaller axial distances and less crosswind entrainment) result in the concentrations without cap to be larger than those with cap. The slightly smaller flow rate results in slightly lower concentration for the runs with calculated $C_{d}$ than the runs with $C_{d}=1$. Along the range of experimental data, no significant difference is seen between the centre-line and off-centreline concentrations for the cases without a velocity cap but significant lower off-centreline concentrations are seen at $1.5 \mathrm{~m}$ height for the cases with a velocity cap. It is seen from the figure that the model accuracy is improved considerably in the near-field while removing the velocity cap. Thus removal of the velocity cap improves the predictions.

In the above hydrogen DISC runs, the ATEX minimum thermodynamic change was predicted by the conservation of momentum equation as opposed to entropy conservation. Alternative options (not available in the ATEX model) include isenthalpic or isothermal expansion. However, these options would have resulted in higher temperatures, consequently more plume rise and therefore smaller concentrations at $1.5 \mathrm{~m}$ height. Thus this would have resulted in an increased underprediction of the results, and we conclude that the conservation-of-momentum option in conjunction with removal of the velocity cap results in the most accurate predictions in the nearfield, and supports its widespread use in the literature.

\section{MODEL VALIDATION - TWO-PHASE RELEASES}

This section details the results of discharge and dispersion calculations associated with pressurised two-phase orifice releases, i.e. the FLADIS ammonia (stagnation pressure 5-7 barg, orifice diameter $6.3 \mathrm{~mm}$ ), Desert Tortoise ammonia ( $\approx 10 \mathrm{barg}, 81$ or $94.5 \mathrm{~mm}$, low humidity), EEC propane (7-9 barg, 4 or $15.5 \mathrm{~mm}$ ), Goldfish HF ( $\approx 8$ barg, 24.2 or $41.9 \mathrm{~mm}$, low humidity), and CO2PIPETRANS $\mathrm{CO}_{2}$ experiments [BP and Shell tests; liquid releases (80-158barg, 5-23C, $1 / 4,1 / 2$ or 1") and vapour releases (146-158 barg, 32-149C, 1/2"). See Witlox and Fernandez (2016) for further details on the input data.

\subsection{Discharge}

DISC discharge calculations have been carried out using the following options:

- Two methods for modelling the expansion from stagnation conditions to vena contracta conditions:

0 the metastable liquid assumption (Phast default): non-equilibrium at vena contracta, liquid remains liquid, vena contracta pressure $=$ ambient pressure

- flashing liquid assumption: equilibrium at vena contracta, flashing may occur upstream of vena contracta

In the literature (e.g. Britter et al., 2011) it is often recommended to apply the metastable liquid assumption for orifice lengths $<0.1 \mathrm{~m}$, and the flashing liquid assumption for orifice lengths $>0.1 \mathrm{~m}$ (i.e. a length of $10 \mathrm{~cm}$ is required to establish equilibrium flow. 
- Three options for ATEX modelling for expansion from vena contracta to final conditions:

- Isentropic

- Conservation of momentum

$\circ$ (default option) One of the two options above, with the option selected which results in minimum thermodynamic change between orifice conditions and final conditions. For all current sets of experiments, it was found that this default option corresponded with the isentropic option. This is with the exception of three hot $\mathrm{CO}_{2}$ releases (BP tests 8,8R and Shell test 14).

Table 1 compares observed flow rates [reported by EU SMEDIS project for the FLADIS, EEC experiments and by Hanna et al. (1991) for the DT, GF experiments] against DISC predictions for both cases of 'metastable liquid' and 'flashing'. The Goldfish predictions are virtually identical for both cases with very close agreement with the data. Predictions for EEC and DT presuming 'flashing' are seen to provide considerably improved predictions compared to the 'metastable liquid' assumption. On the other hand, FLADIS results are best presuming 'metastable liquid', with significant under-prediction presuming 'flashing'. Overall the 'metastable liquid' is seen to provide conservative results, with an over-prediction of the observed flow rates. Note there is an inherent inaccuracy in the measured flow rates with e.g. an accuracy of $18 \%$ quoted by Nielsen and Ott (1996) for FLADIS. A more accurate estimate of the input as well a more accurate method of modelling could possibly be obtained by means of a more thorough analysis of the experimental data sets. However this was not part of scope of the current work.

\begin{tabular}{|c|c|c|c|c|c|c|c|c|c|c|c|c|c|c|}
\hline & $\begin{array}{l}F L \\
A D \\
9\end{array}$ & $\begin{array}{l}F L \\
A D \\
16\end{array}$ & $\begin{array}{l}F L \\
A D \\
24\end{array}$ & $\begin{array}{l}\text { EE } \\
C \\
170\end{array}$ & $\begin{array}{l}E E \\
C \\
36 \\
0\end{array}$ & $\begin{array}{l}E E \\
C \\
55 \\
0\end{array}$ & $\begin{array}{l}E E \\
C \\
56 \\
0\end{array}$ & $\begin{array}{l}D T \\
1\end{array}$ & $\begin{array}{l}\text { DT } \\
2\end{array}$ & $\begin{array}{l}D T \\
3\end{array}$ & $\begin{array}{l}D T \\
4\end{array}$ & $\begin{array}{l}G F \\
1\end{array}$ & $\begin{array}{l}G F \\
2\end{array}$ & $\begin{array}{l}G F \\
3\end{array}$ \\
\hline $\begin{array}{l}\text { FLOW } \\
\text { RATE }\end{array}$ & & & & & & & & & & & & & & \\
\hline $\begin{array}{l}\text { Observed, } \\
\mathrm{kg} / \mathrm{s}\end{array}$ & 0.4 & $\begin{array}{l}0.2 \\
7\end{array}$ & $\begin{array}{l}0.4 \\
6\end{array}$ & 2.9 & $\begin{array}{l}0.1 \\
1\end{array}$ & 3 & 3 & 79. & $\begin{array}{l}11 \\
1.5\end{array}$ & $\begin{array}{l}13 \\
0.7\end{array}$ & $\begin{array}{l}96 . \\
7\end{array}$ & $\begin{array}{l}27 . \\
67\end{array}$ & $\begin{array}{l}10 . \\
46\end{array}$ & $\begin{array}{l}10 . \\
27\end{array}$ \\
\hline $\begin{array}{l}\text { Predicted } \\
\text { (metastable) }\end{array}$ & $\begin{array}{l}0.5 \\
7\end{array}$ & $\begin{array}{l}0.2 \\
5\end{array}$ & $\begin{array}{l}0.5 \\
1\end{array}$ & & & $\begin{array}{l}3.5 \\
9\end{array}$ & $\begin{array}{l}3.6 \\
1\end{array}$ & $\begin{array}{l}11 \\
6.8\end{array}$ & $\begin{array}{l}16 \\
7.8\end{array}$ & $\begin{array}{l}16 \\
9.2\end{array}$ & $\begin{array}{l}17 \\
2.2\end{array}$ & $\begin{array}{l}30 . \\
75\end{array}$ & $\begin{array}{l}10 . \\
47\end{array}$ & $\begin{array}{l}10 . \\
54\end{array}$ \\
\hline $\begin{array}{l}\text { Predicted } \\
\text { (flashing) }\end{array}$ & $\begin{array}{l}0.1 \\
5\end{array}$ & $\begin{array}{l}0.0 \\
8\end{array}$ & $\begin{array}{l}0.1 \\
3\end{array}$ & $\begin{array}{l}2.7 \\
8\end{array}$ & $\begin{array}{l}0.1 \\
1\end{array}$ & $\begin{array}{l}2.8 \\
9\end{array}$ & $\begin{array}{l}2.9 \\
2\end{array}$ & $\begin{array}{l}63 . \\
0\end{array}$ & $\begin{array}{l}11 \\
6.1\end{array}$ & $\begin{array}{l}11 \\
0.9\end{array}$ & $\begin{array}{l}10 \\
8.2\end{array}$ & $\begin{array}{l}30 . \\
69\end{array}$ & $\begin{array}{l}10 . \\
46\end{array}$ & $\begin{array}{l}10 . \\
52\end{array}$ \\
\hline $\begin{array}{l}\text { Pred./Obs. } \\
\text { (metastable) } \\
\text { Pred./Obs. } \\
\text { (flashing) }\end{array}$ & $\begin{array}{l}\mathbf{1 . 4} \\
\mathbf{3} \\
0.3 \\
8 \\
\end{array}$ & $\begin{array}{l}\mathbf{0 . 9} \\
\mathbf{2} \\
0.2 \\
8 \\
\end{array}$ & $\begin{array}{l}1.1 \\
1 \\
0.2 \\
9 \\
\end{array}$ & $\begin{array}{l}1.1 \\
9 \\
0.9 \\
6 \\
\end{array}$ & $\begin{array}{l}1.8 \\
6 \\
\mathbf{0 . 9} \\
\mathbf{9} \\
\end{array}$ & $\begin{array}{l}1.2 \\
0 \\
\mathbf{0 . 9} \\
6 \\
\end{array}$ & $\begin{array}{l}1.2 \\
0 \\
\mathbf{0 . 9} \\
\mathbf{7} \\
\end{array}$ & $\begin{array}{l}1.4 \\
6 \\
0.7 \\
9 \\
\end{array}$ & $\begin{array}{l}1.5 \\
1 \\
1.0 \\
4\end{array}$ & $\begin{array}{l}1.2 \\
9 \\
0.8 \\
5 \\
\end{array}$ & $\begin{array}{l}1.7 \\
8 \\
1.1 \\
2 \\
\end{array}$ & $\begin{array}{l}1.1 \\
1 \\
1.1 \\
1\end{array}$ & $\begin{array}{l}1.0 \\
0 \\
1.0 \\
0 \\
\end{array}$ & $\begin{array}{l}1.0 \\
3 \\
1.0 \\
2 \\
\end{array}$ \\
\hline $\begin{array}{l}\text { SMEDIS } \\
\text { Liquid } \\
\text { Fraction } \\
\text { Velocity } \\
(\mathrm{m} / \mathrm{s})\end{array}$ & $\begin{array}{l}0.8 \\
4 \\
65 . \\
17\end{array}$ & $\begin{array}{l}0.8 \\
3 \\
67 . \\
85\end{array}$ & $\begin{array}{l}0.8 \\
3 \\
55 . \\
87\end{array}$ & $\begin{array}{l}0.7 \\
2 \\
85 . \\
21\end{array}$ & $\begin{array}{l}0.7 \\
1 \\
84 . \\
2\end{array}$ & $\begin{array}{l}0.7 \\
0 \\
68 . \\
5\end{array}$ & $\begin{array}{l}0.7 \\
0 \\
89 . \\
0\end{array}$ & $\begin{array}{l}0.8 \\
2 \\
90 . \\
3\end{array}$ & $\begin{array}{l}0.8 \\
2 \\
72 . \\
7\end{array}$ & - & - & - & - & - \\
\hline
\end{tabular}




\begin{tabular}{|c|c|c|c|c|c|c|c|c|c|c|c|c|c|c|}
\hline $\begin{array}{l}\text { DISC } \\
\text { (metastable; } \\
\text { conserve } \\
\text { momentum) } \\
\text { Liquid } \\
\text { Fraction } \\
\text { Velocity } \\
(\mathrm{m} / \mathrm{s}) \\
\text { SMD droplet } \\
\text { size }(\mu \mathrm{m}) \\
\end{array}$ & $\begin{array}{l}0.8 \\
4 \\
49 . \\
3 \\
144 \\
\end{array}$ & $\begin{array}{l}0.8 \\
3 \\
53 . \\
7 \\
122\end{array}$ & $\begin{array}{l}0.8 \\
6 \\
43 . \\
6 \\
187\end{array}$ & $\begin{array}{l}0.7 \\
0 \\
59 . \\
4 \\
45\end{array}$ & $\begin{array}{l}0.6 \\
9 \\
53 . \\
3 \\
57\end{array}$ & $\begin{array}{l}0.6 \\
9 \\
62 . \\
1 \\
40\end{array}$ & $\begin{array}{l}0.6 \\
9 \\
62 . \\
5 \\
41\end{array}$ & $\begin{array}{l}0.8 \\
0 \\
62 \\
2 \\
10 \\
8\end{array}$ & $\begin{array}{l}0.8 \\
1 \\
65 . \\
4 \\
98\end{array}$ & $\begin{array}{l}0.8 \\
0 \\
66 . \\
3 \\
97\end{array}$ & $\begin{array}{l}0.8 \\
0 \\
67 . \\
8 \\
93\end{array}$ & $\begin{array}{l}0.8 \\
6 \\
41 . \\
1 \\
36 \\
0 \\
\end{array}$ & $\begin{array}{l}0.8 \\
7 \\
41 . \\
7 \\
35 \\
4\end{array}$ & $\begin{array}{l}0.8 \\
6 \\
42 . \\
2 \\
35 \\
4\end{array}$ \\
\hline $\begin{array}{l}\text { DISC } \\
\text { (flashing; } \\
\text { conserve } \\
\text { momentum) } \\
\text { Liquid } \\
\text { Fraction } \\
\text { Velocity } \\
(\mathrm{m} / \mathrm{s}) \\
\text { SMD droplet } \\
\text { size }(\mu \mathrm{m})\end{array}$ & $\begin{array}{l}0.8 \\
4 \\
122 \\
.7 \\
\\
23\end{array}$ & $\begin{array}{l}0.8 \\
3 \\
119 \\
.4 \\
\\
25\end{array}$ & $\begin{array}{l}0.8 \\
6 \\
113 \\
.1 \\
\\
28\end{array}$ & $\begin{array}{l}0.7 \\
0 \\
65 . \\
6 \\
325\end{array}$ & $\begin{array}{l}0.6 \\
9 \\
82 . \\
2 \\
26 \\
8\end{array}$ & $\begin{array}{l}0.6 \\
9 \\
68 . \\
3 \\
31 \\
9\end{array}$ & $\begin{array}{l}0.6 \\
9 \\
68 . \\
7 \\
31 \\
8\end{array}$ & $\begin{array}{l}0.8 \\
1 \\
82 . \\
2 \\
27 \\
5\end{array}$ & $\begin{array}{l}0.8 \\
1 \\
71 . \\
1 \\
31 \\
6\end{array}$ & $\begin{array}{l}0.8 \\
0 \\
75 . \\
0 \\
30 \\
4\end{array}$ & $\begin{array}{l}0.8 \\
0 \\
79 . \\
2 \\
29 \\
3\end{array}$ & $\begin{array}{l}0.8 \\
6 \\
41 . \\
3 \\
34 \\
8\end{array}$ & $\begin{array}{l}0.8 \\
7 \\
41 . \\
8 \\
34 \\
4\end{array}$ & $\begin{array}{l}0.8 \\
6 \\
42 . \\
3 \\
34 \\
3\end{array}$ \\
\hline $\begin{array}{l}\text { DISC } \\
\text { (metastable; } \\
\text { isentropic) } \\
\text { Liquid } \\
\text { Fraction } \\
\text { Velocity } \\
(\mathrm{m} / \mathrm{s}) \\
\text { SMD droplet } \\
\text { size }(\mu \mathrm{m})\end{array}$ & $\begin{array}{l}0.8 \\
5 \\
201 \\
.8 \\
\\
113\end{array}$ & $\begin{array}{l}0.8 \\
4 \\
216 \\
.9 \\
\\
102\end{array}$ & $\begin{array}{l}0.8 \\
7 \\
178 \\
.1 \\
131\end{array}$ & $\begin{array}{l}0.7 \\
3 \\
172 \\
.0 \\
141\end{array}$ & $\begin{array}{l}0.7 \\
2 \\
17 \\
6.5 \\
13 \\
7\end{array}$ & $\begin{array}{l}0.7 \\
2 \\
17 \\
8.0 \\
13 \\
6\end{array}$ & $\begin{array}{l}0.7 \\
2 \\
18 \\
0.4 \\
13 \\
4\end{array}$ & $\begin{array}{l}0.8 \\
2 \\
24 \\
6.0 \\
84\end{array}$ & $\begin{array}{l}0.8 \\
3 \\
24 \\
1.0\end{array}$ & $\begin{array}{l}0.8 \\
2 \\
24 \\
9.5\end{array}$ & $\begin{array}{l}0.8 \\
2 \\
25 \\
8.1 \\
\\
77\end{array}$ & $\begin{array}{l}0.8 \\
6 \\
70 . \\
7 \\
26 \\
5\end{array}$ & $\begin{array}{l}0.8 \\
8 \\
66 . \\
0 \\
27 \\
5\end{array}$ & $\begin{array}{l}0.8 \\
7 \\
69 . \\
9 \\
26 \\
7\end{array}$ \\
\hline
\end{tabular}

Table 1. Flow rate and post-expansion data predictions (FLADIS, EEC, Desert Tortoise, Goldfish)

Table 1 secondly compares predictions of post-expansion data [liquid fraction, velocity, Sauter Mean Diameter (SMD) for droplet size] using the range of model assumptions as described above. It also compares these predictions against values of liquid fraction and velocity provided as part of the SMEDIS project. The data for final liquid fraction provided by SMEDIS are seen to be in close agreement with the DISC predictions. The DISC predictions of final velocity presuming metastable liquid assumption are lower than presuming 'flashing' upstream of the orifice. DISC predictions of velocities presuming conservation of entropy result in significant larger velocities than presuming conservation of momentum. For the case of the FLADIS experiments, SMEDIS values for velocity are closest to the DISC predictions presuming metastable liquid and conservation of momentum. On the other hand, for the EEC and Desert Tortoise experiments, the SMEDIS values are closest to the DISC predictions presuming flashing and conservation of momentum. Using the isentropic approach, DISC predicts post flash velocities which are much higher than those provided as part of the SMEDIS project. 
For the $\mathrm{CO}_{2}$ experiments close results were seen between all post-expansion data between the metastable liquid and flashing assumptions. The isentropic option results in considerably larger velocities and larger liquid fractions than the conservation-of-momentum option. See Witlox and Fernandez (2016) for further details.

\subsection{Dispersion}

Dispersion calculations were carried out using the latest version of the UDM, which following rainout models the time-varying dispersion using the so-called 'observer' concept (Witlox and Harper, 2014). Figure 6, Figure 7 and Figure 8 include results for Desert Tortoise experiment 3, EEC test 550, and FLADIS test 24, respectively. The concentration plot includes graphs versus downwind distance for the maximum concentration at the measurement height. In the width plot, the cloud width has been calculated using the cloud width definition from either the EU project SMEDIS or from Hanna et al. (2011). The plots include results based on three different discharge model assumptions: metastable liquid and conservation of momentum (black lines), flashing at the orifice and conservation of momentum (red lines), metastable liquid and isentropic (purple lines); yellow markers denote experimental data points. The UDM initial values for liquid fraction, velocity and droplet size were based on these DISC discharge assumptions, while the input UDM flow rate was chosen to be based on the observed flow rate.

The following conclusions can be drawn:

- Figure 6a (DT03) illustrates the predicted discontinuity of the concentration at the point of rainout for the case of conservation of momentum.

- For EEC550 rainout was predicted to occur only for the conservation-of-momentum flashing case. The pool vapour added back to the cloud results in an increase of the concentration at $0.05 \mathrm{~m}$ height (Figure 7a).

- The conservation-of-momentum assumption for atmospheric expansion gives the closest agreement to the experiments. In general, the assumption of metastable liquid for the expansion from stagnation to orifice conditions shows slightly better agreement. The isentropic option results in too large concentrations for Desert Tortoise 3 (caused by absence of rainout due to smaller SMD and larger initial velocities), while it is resulting in too low concentrations for EEC550 (caused by larger jet entrainment due to larger post-expansion velocity). 


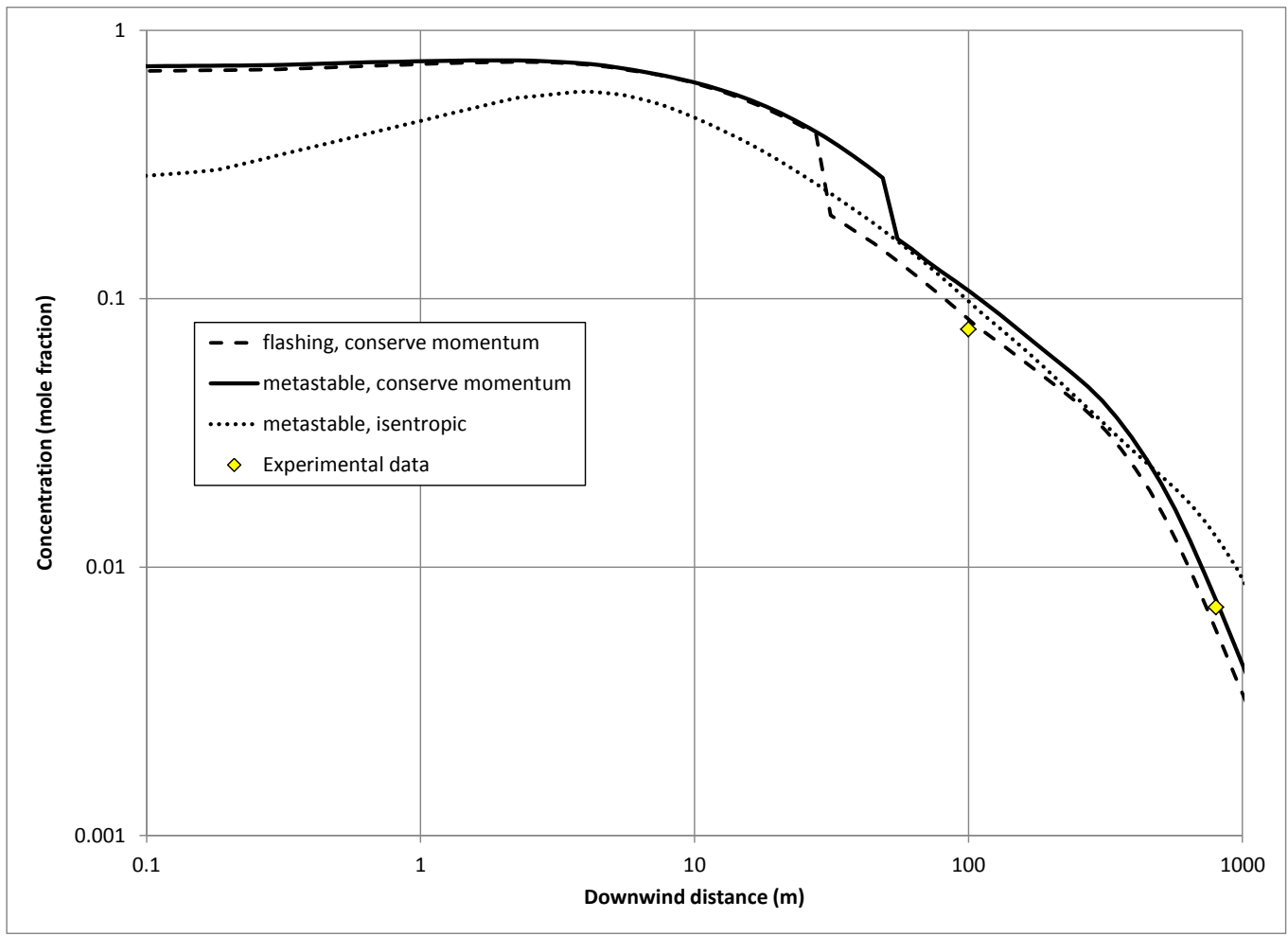

(a) maximum concentration at measurement height ( $1 \mathrm{~m})$

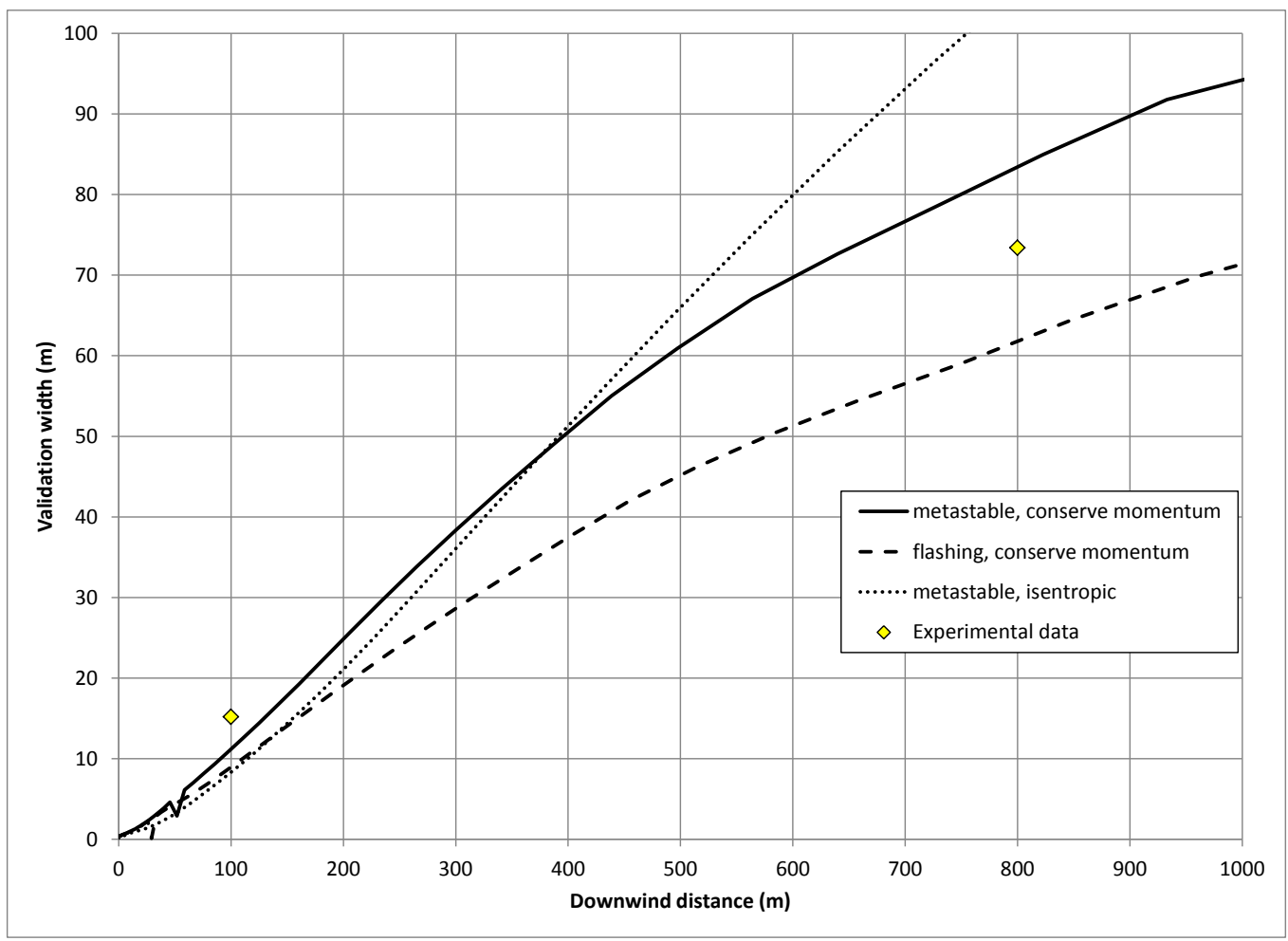

(b) width

Figure 6. Desert Tortoise 3 - concentration and width validation - vary discharge model options 


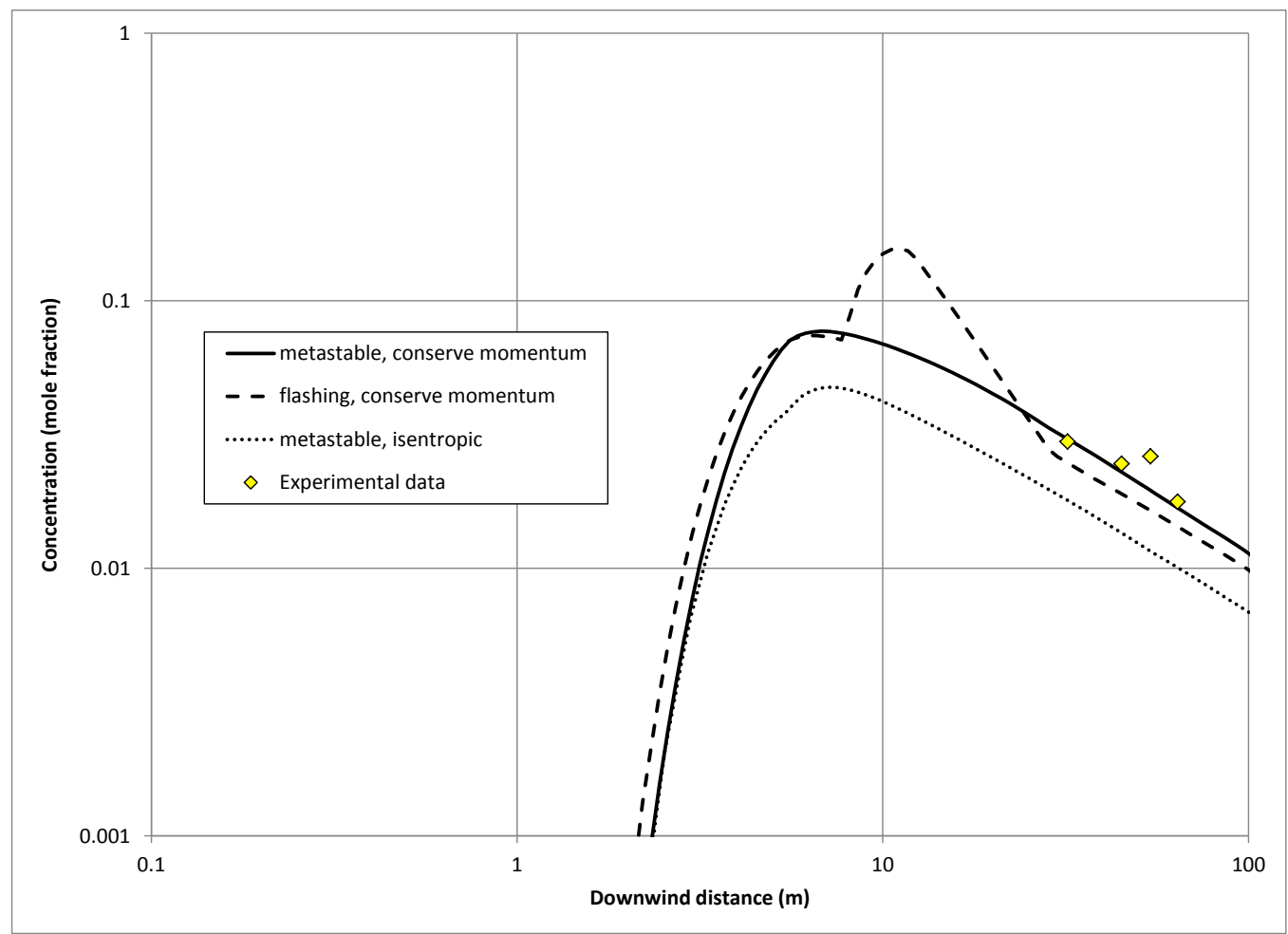

(a) maximum concentration at measurement height $(0.05 \mathrm{~m})$

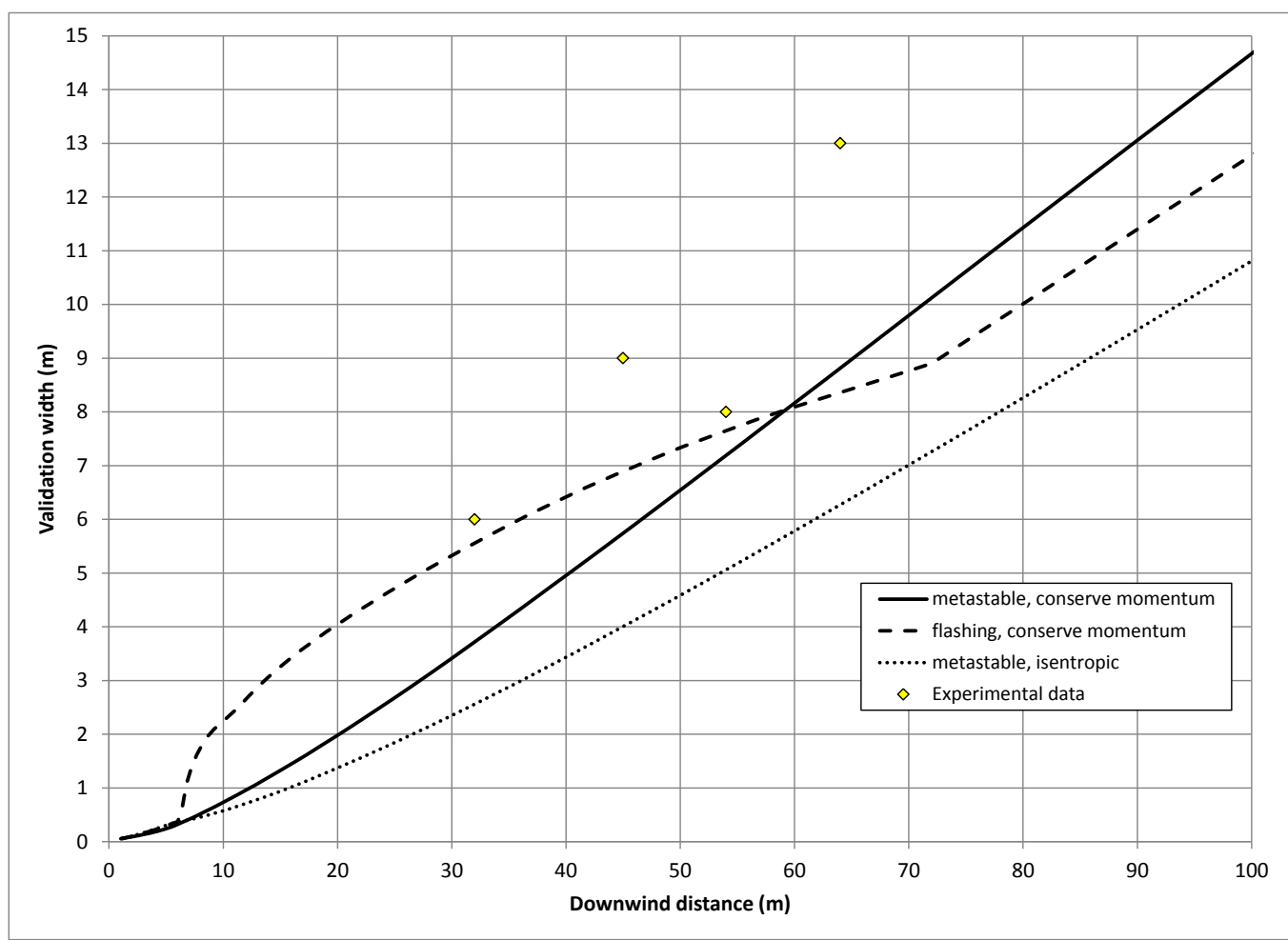

(b) width

Figure 7. EEC 550 - concentration and width validation - vary discharge model options 


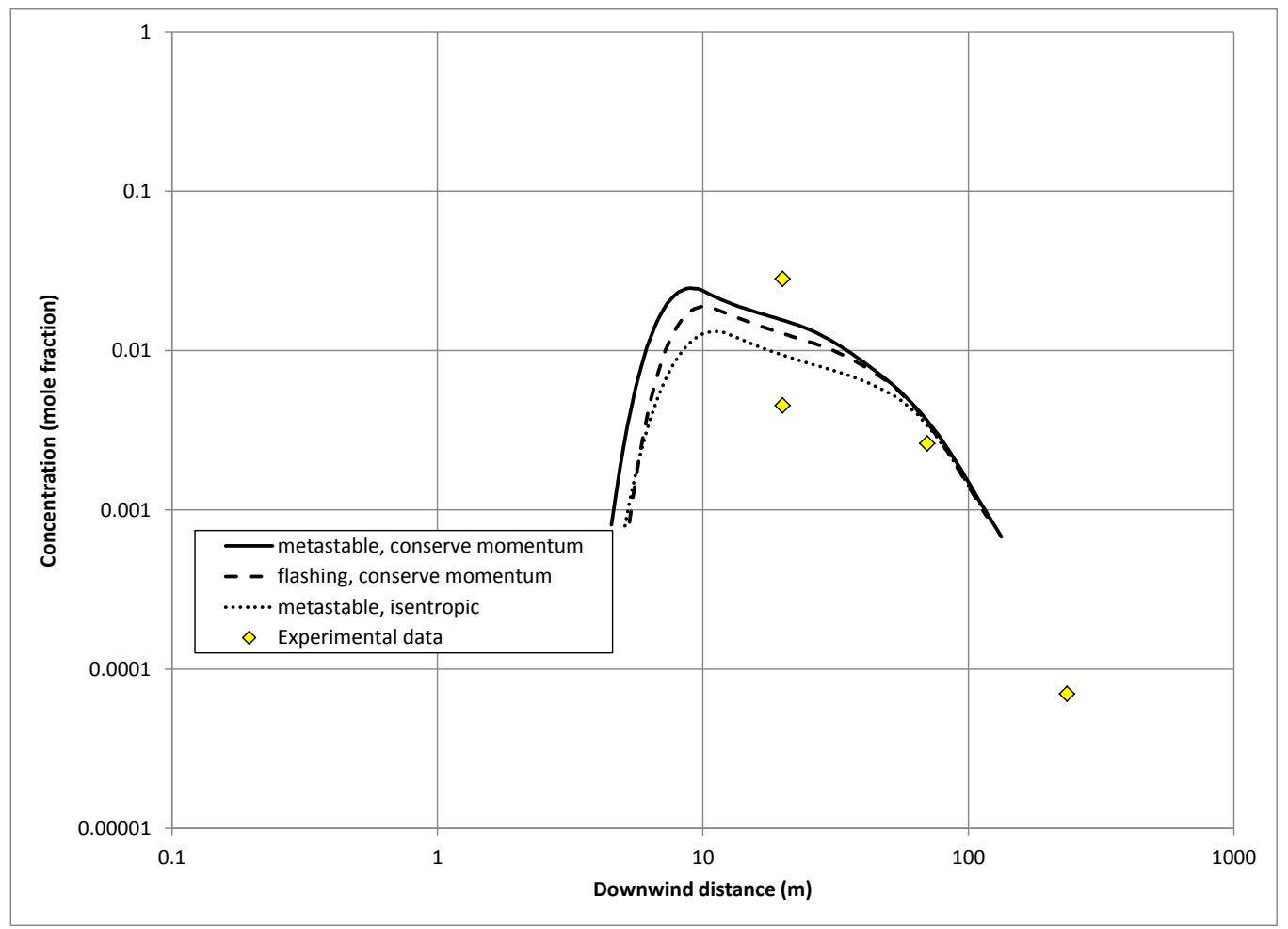

(a) maximum concentration at measurement height $(0.5 \mathrm{~m})$

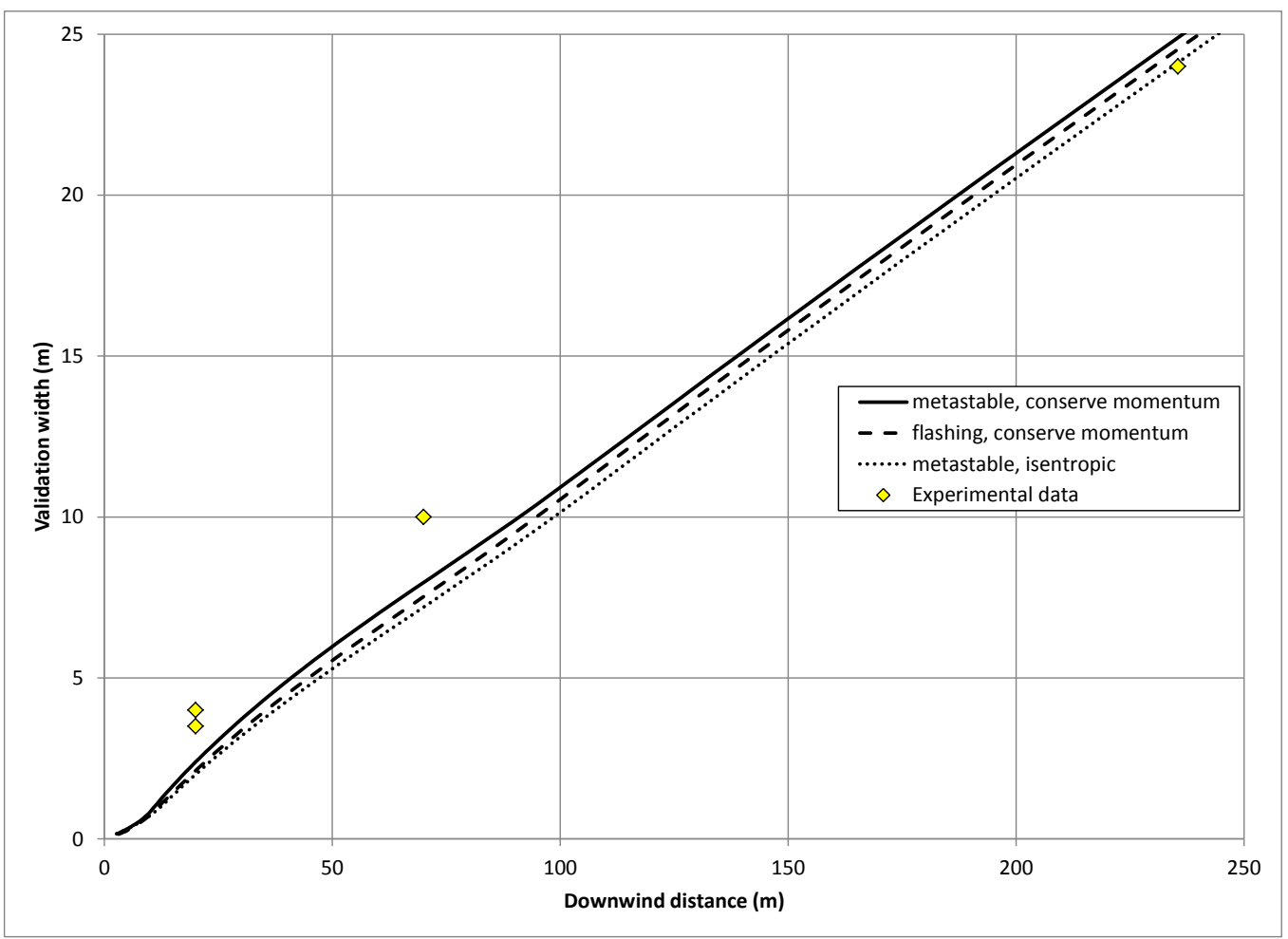

(b) width

Figure 8. FLADIS 24 - concentration and width validation - vary discharge model options 


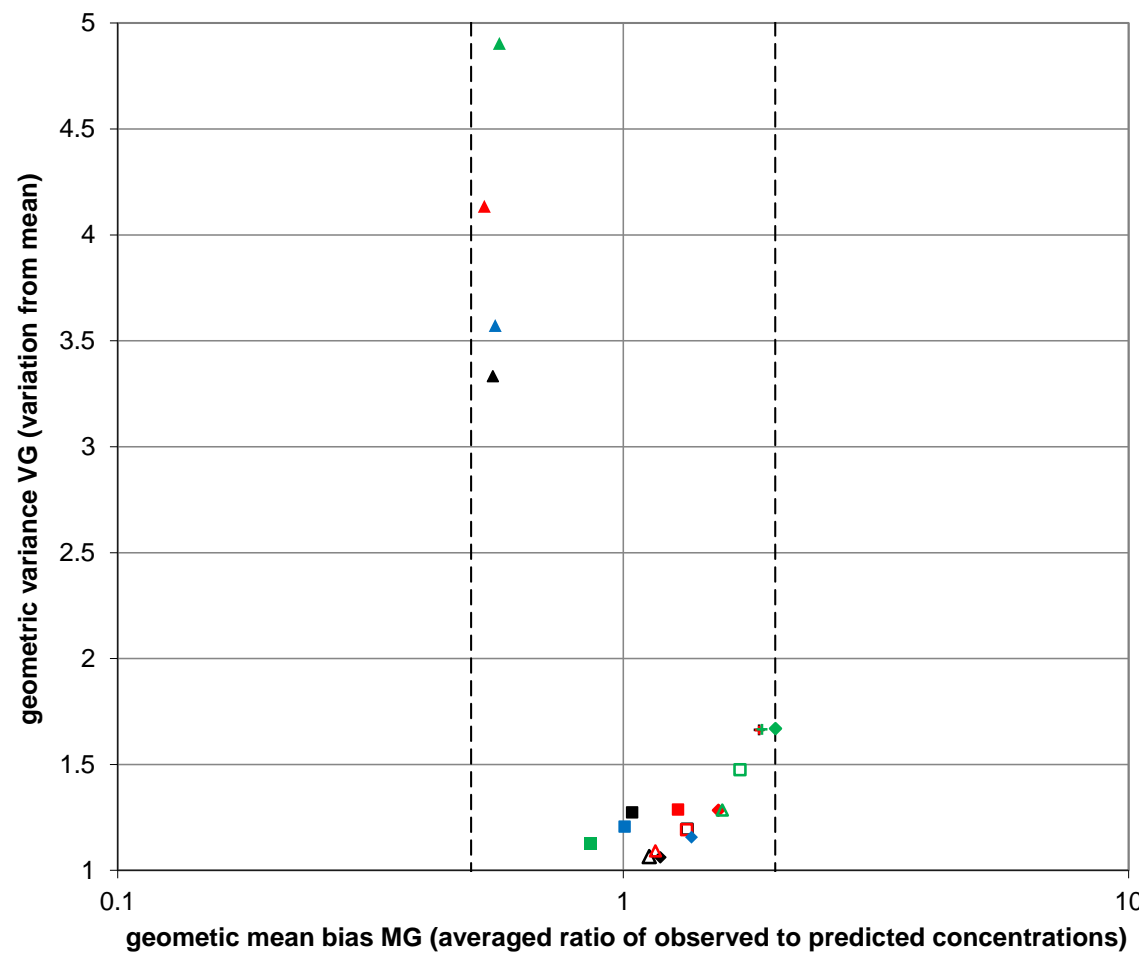

\section{- - - Under_by_2}

- - - Over_by_2

- Desert Tortoise_momentum_metastable

- EEC_momentum_metastable

- FLADIS_momentum_metastable

+ Goldfish_momentum_metastable

口 CO2_BP_momentum_metastable

$\Delta$ CO2_Shell_momentum_metastable

- Desert Tortoise_momentum_flashing

- EEC_momentum_flashing

\ FLADIS_momentum_flashing

+ Goldfish_momentum_flashing

口 CO2_BP_momentum_flashing

$\triangle$ CO2_Shell_momentum_flashing

- Desert Tortoise_smedis

- EEC_smedis

4 FLADIS_smedis

- Desert Tortoise_isentropic_metastable

- EEC_isentropic_metastable

^ FLADIS_isentropic_metastable

+ Goldfish_isentropic_metastable

口 CO2_BP_isentropic_metastable

$\triangle$ CO2_Shell_isentropic_metastable

(a) Concentration

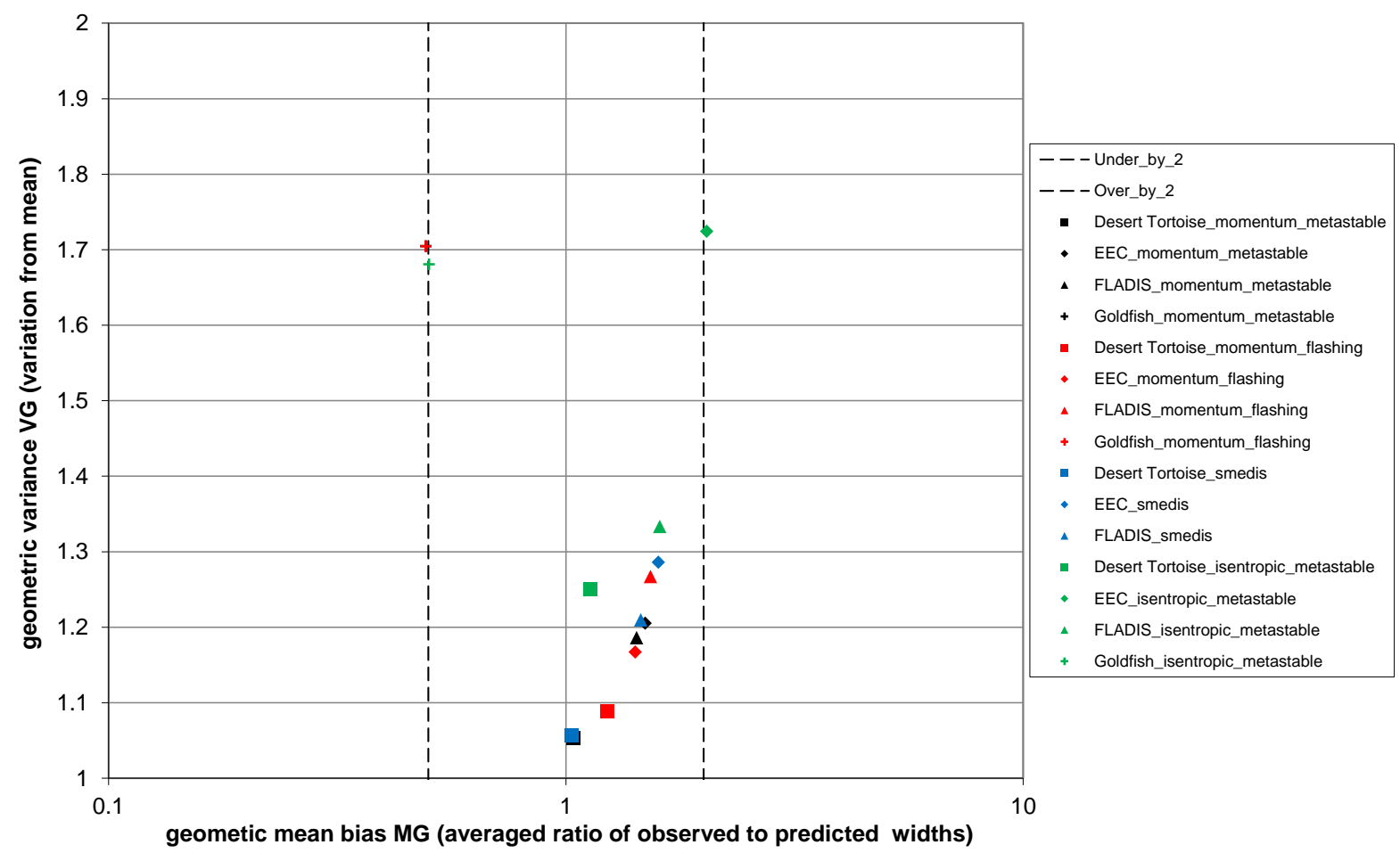

(b) Width

Figure 9. MG/VG concentration plot (flashing two-phase jets ; vary DISC/ATEX options) 
For a given experimental dataset, it is common practice (Hanna et al., 1991) to calculate the geometric mean bias MG (averaged ratio of observed to predicted concentrations; $M G<1$ overprediction and $\mathrm{MG}>1$ under-prediction) and the geometric variance $\mathrm{VG}$ (variation from mean; minimum value $=1$ ). Ideally, $\mathrm{MG}$ and VG would both equal 1.0. Geometric mean bias (MG) values of 0.5 and 2.0 represent a factor of 2 in over-predicting and under-predicting the mean, respectively. Likewise, a geometric variance (VG) of about 1.6 indicates scatter from observed data to predicted data by a factor of 2 .

Figure 9 shows the summary MG/VG plot for concentration and widths predictions for twophase jet releases of propane (EEC), HF (Goldfish), ammonia (FLADIS and Desert Tortoise) and $\mathrm{CO}_{2}$ (BP and Shell). The figures compare the accuracy of the various expansion methods for predicting concentration and cloud width, and it's been colour coded for easier comparison:

- Conservation of momentum and metastable liquid predictions are shown with black markers

- Conservation of momentum and flashing at the orifice, in red markers

- SMEDIS input data, in blue markers

- Isentropic and metastable liquid, with green markers

In general, it can be seen that applying conservation of momentum with metastable liquid yields more accurate MG/VG values. The overall results can be summarised as follows:

- Apart from FLADIS, all MG values are well within the range of [0.5, 2], and variances VG are less than 1.6 which is normally considered to be excellent agreement with the experimental data.

- Desert Tortoise, EEC and $\mathrm{CO}_{2} \mathrm{BP}$ and Shell sets of tests show very good accuracy

- Desert Tortoise results shows the best agreement using the metastable-liquid and conservation-of-momentum assumption and corresponds well to SMEDIS data. Metastable-liquid and isentropic assumption lead to higher concentrations (lower MG values), which is due to the absence of rainout. Flashing-liquid and conservation-of momentum assumptions lead to lower concentrations due to the larger rainout fraction predicted by the flashing assumption.

- For EEC, rainout was predicted only for conservation of momentum and flashing at the orifice. Thus lower concentrations are obtained for flashing than for metastable liquid when applying conservation of momentum. However, the higher final velocities predicted by the isentropic expansion results in the lower concentrations predictions at a given height. The better agreement for concentration predictions was observed when applying metastable liquid and conservation-of momentum assumption. Conversely, for the widths, applying conservation of momentum with flashing yield better agreement.

- $\mathrm{CO}_{2} \mathrm{BP}$ and Shell results show a similar trend as EEC. Applying isentropic expansion with metastable liquid assumption results in lower predicted concentrations due to the higher final velocities. Results for conservation of momentum with flashing and metastable liquid assumptions produce very similar results.

- FLADIS predictions of concentration show larger values for the geometric variance. The better agreement was observed for conservation of momentum and metastable liquid. 
- Goldfish results show accurate prediction of the maximum concentration and an underprediction of the cloud width. Very little difference was found between the predictions for conservation of momentum or isentropic and flashing at the orifice or metastable liquid assumptions.

\section{Conclusions and future work}

1. For flashing liquid orifice releases, the metastable liquid assumption provides most accurate predictions of the flow rate for most of the available experimental data for orifice releases. This option is also in line with recommendations from the literature (for orifice lengths $<0.1$ $\mathrm{m})$. Furthermore it is conservative compared to the assumption of allowing flashing upstream of the orifice. Thus this option is recommended to be retained as the default Phast assumption.

2. The conservation-of-momentum option in conjunction with the absence of a velocity cap for final post-expansion velocity overall provides the most accurate predictions for near-field concentrations.

a. For liquid releases the velocity cap of $500 \mathrm{~m} / \mathrm{s}$ is not applicable. For gas releases, the velocity cap is mostly relevant for those gases where the speed of sound is very large, i.e. in particular for hydrogen and up to a lesser extent for natural gas (methane). Thus removal of the velocity cap was shown to significantly increase the accuracy of nearfield concentration predictions for hydrogen releases, while there was only a small difference for natural-gas releases. In both cases there is a slight under-prediction of the experimental data.

b. For gas releases, the conservation-of-momentum option is normally selected (using the default Phast 7.2 option of minimum thermodynamic change), since the isentropic option results in larger final post-expansion velocities and hence smaller temperatures. It is also noted that isenthalpic or isothermal options are expected to reduce the accuracy for the validation against the hydrogen experiments.

c. For liquid releases, the isentropic option is normally selected using the default Phast 7.2 option. In case of rainout, this option currently remains recommended since the Phast rainout correlation for superheated flashing jets is based on a best fit against experimental data using this isentropic option (Witlox and Harper, 2013). However for releases without rainout, conservation-of-momentum is recommended to be selected. Thus as part of potential future work the Phast rainout correlation for superheated flashing jets may be considered to be modified to provide a best fit against experimental data in conjunction with the conservation-of-momentum option.

3. The UDM dispersion model is currently based on isenthalpic mixing between the released pollutant and the ambient moist air. Thus it does not account for the initial kinetic energy of the released pollutant (velocity $u_{f}$ ), and therefore it is inconsistent with the ATEX conservation-of-energy equation (3). Consequently the UDM could be considered to be modified with the addition of a kinetic-energy term in conjunction with redoing the UDM model validation. 


\section{ACKNOWLEDGEMENTS}

Financial support of the work reported in this paper was provided by DNV GL Software and RIVM (Dutch Government). The contents of this paper including any opinions and/or conclusions expressed, are those of the authors alone and do not necessarily reflect the policy of these organizations.

\section{REFERENCS}

Birch, A.D., Brown, D.R., Dodson, M.G., and Swaffield, F., 1984, The structure and concentration decay of high pressure jets of natural gas, Combustion Science Technology, 36: 249-261

Birch, A.D., Hughes, D.J., and Swaffield, F., 1987, Velocity decay of high pressure jets, Combustion Science Technology, 52: 161-171

Britter, R., Weil, J., Leung, J., and Hanna, S., 2011, Toxic Industrial Chemical (TIC) source emissions model improvements for pressurised liquefied gases, Atmospheric Environment 45: 125

Daish, N.C., Britter, R.E., Linden, P.F., Jagger. S.F., and Carissimo, B., 1999, SMEDIS:

Scientific Model Evaluation techniques applied to dense gas dispersion models in complex situations", International Conference and Workshop on Modelling the Consequences of Accidental Releases of Hazardous Materials, CCPS, San Francisco, California, September 28 October 1

Hanna, S.R., D.G.Strimaitis, and J.C.Chang, 1991, Hazard response modelling uncertainty (A quantitative method), Sigma Research Corp. report, Westford, MA for the API

Nielsen, M. and Ott, S., 1996, FLADIS field experiments, Final report Ris $\emptyset-R-898(E N)$, Ris $\emptyset$

National Laboratory, Roskilde, Denmark

Paris, A., Spicer, T., and Havens, J., 2005, Modeling the initial conditions of two-phase jet flow through an orifice after depressurisation, Mary Kay O'Connor Process Safety Center Symposium, Texas A\&M University, College Station

Roberts, P.T., Shirvill, L.C., Roberts, T.A., Butler, C.J. and Royle, M., 2006, Dispersion of hydrogen from high-pressure sources, Hazards XIX conference, Manchester, UK

Skottene, M. and Holm, A., 2008, H2 release and jet dispersion - validation of Phast and KFX, Report 2008-0073, DNV Research, Høvik, Norway

Wareing, C.J., Fairweather, M., Peakall, J., Keevil, G., Falle, S.A.E.G., and Woolley, R.M., 2013, Numerical modelling of particle-laden sonic $\mathrm{CO}_{2}$ jets with experimental validaton", $A I P$ Conference Proceedings 1558: 92-102, Rhodes, Greece

Witlox, H.W.M. and Bowen, P., 2002, Flashing liquid jets and two-phase dispersion - A review, Work carried out by DNV for HSE, Exxon-Mobil and ICI Eutech, HSE Books, Contract research report 403/2002

Witlox, H.W.M. and Fernandez, M., 2016, Atmospheric expansion modelling - literature review, model refinement and validation, Report no. 984B0034, DNV GL Software, Part of future Phast Technical Documentation, London (2016) 
Witlox, H.W.M. and Harper, M., 2013, Two-phase jet releases, droplet dispersion and rainout, I. Overview and model Validation, Journal of Loss Prevention in the Process Industries 26: 453461.

Witlox, H.W.M and Harper, M., 2014, Modelling of time-varying dispersion for releases including potential rainout, Process Safety Progress 33(3): 265-273

Witlox, H.W.M., and Holt, A., 1999, A unified model for jet, heavy and passive dispersion including droplet rainout and re-evaporation, International Conference and Workshop on Modelling the Consequences of Accidental Releases of Hazardous Materials, CCPS, San Francisco, California, Sep. 28 - Oct. 1, pp. 315-344 